\title{
The Planetary Accounting Framework: a novel, quota-based approach to understanding the impacts of any scale of human activity in the context of the Planetary Boundaries
}

\author{
Kate Meyer ${ }^{*}$ (i) and Peter Newman
}

\begin{abstract}
Background: Human impacts on the environment are so great that we are at risk of changing the state of the planet from one that is hospitable to one that is hostile to humanity. Scientists have proposed nine Planetary Boundaries, global environmental limits within which the risk of changing the state of the planet is low, but already, four have been exceeded.

Policy makers and scientists want to use the Planetary Boundaries as a tool for global environmental management. However, the Boundaries were intended as a gauge of the magnitude and urgency of the situation, not as a guide to resolving it. They are not easily applied to personal or policy action that is measurable or scalable. Here we show how the Planetary Boundaries can be translated into a framework for the management of the global environment, the Planetary Accounting Framework.
\end{abstract}

Results: The Planetary Accounting Framework is a new approach to environmental accounting in which environmental impacts are compared to global limits, the Planetary Quotas. The Planetary Quotas are limits for human activity, derived from the Planetary Boundaries. Each Quota is a limit for an "environmental currency" such as carbon dioxide emissions, or reforestation that can be scaled and compared to human activity using existing environmental assessment frameworks. The Quotas and Framework were developed by combining three key theories. Management theory shows that a multilevel, poly-scalar approach is needed to manage the global environment. Accounting theory highlights the importance of accounting against limits if a realistic approach to achieving change is sought. Environmental accounting theory demonstrates that there are different categories of indicators, and that only if indicators are uniformly in the pressure category can human activity be related to a limit and scaled accordingly.

Conclusions: The Planetary Accounting Framework shows how individual actions, strategies by firms, city level infrastructure, and national policies can be expressed in terms of the Planetary Boundaries. Decisions can now be made at different levels or sectors regarding policy, planning, technology, business operations, legislation, and behaviour in the context of global environmental limits. It enables the practical application and communication of the Planetary Boundaries to different scales of human activity.

Keywords: Planetary boundaries, Environmental accounting, Poly-scalar management, Environmental impact assessment, Planetary accounting, Planetary quotas, Policy, Behaviour, Science

\footnotetext{
* Correspondence: kate@planetaryaccounting.org

Peter Newman was not involved in any of the reviewing process associated

with this paper

Curtin University, Bentley, Australia
}

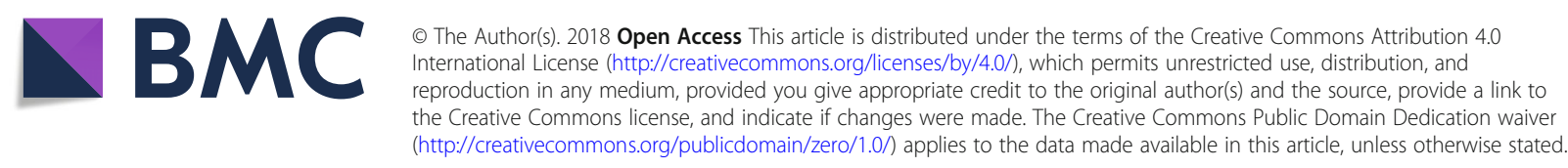




\section{Background}

The sum of the planet's physical, chemical and biological processes is known as the Earth system. The Earth system comprises many interconnected processes (such as evaporation, transpiration, and photosynthesis) that store, transfer, and transform matter and energy according to the laws of physics and biogeochemistry [1].

When Earth system processes are in balance, the Earth system can operate in a particular state for many thousands of years. However, major disturbances to Earth-system processes can lead to an abrupt change of state. The transition from the most recent glacial period - the Younger Dryas is an example of how rapid the change can be. Some regions are believed to have experienced more than $10{ }^{\circ} \mathrm{C}$ of warming in a single decade [2].

Homo sapiens evolved approximately 300,000 years ago [3]. For more than 280,000 years, humans subsisted as hunter gatherers who moved to suitable areas where they could survive. The Holocene is the period of time which began approximately 11,650 years before present (taken as the year 2000) [2]. The relatively warm and stable temperatures in the Holocene epoch saw the rapid development of humans from hunter gatherers to urban and agricultural settled societies $[4,5]$. The state of the planet during the Holocene - henceforth referred to as a Holocene-like state - is the only environmental state of the planet in which we know settled societies can thrive $[4,5]$.

Scientists believe that the Holocene is over $[4,6,7]$. They believe we are in the transition to a new epoch, the Anthropocene, which roughly translates to "the human era" [6]. The state of the planet during the
Anthropocene is yet to be determined; it could be a Holocene-like state, or it could be a much warmer state. A warmer Anthropocene is unlikely to occur through gradual and linear change [8]. Predictions are for non-linear, rapid, and potentially irreversible and sustained change to the climate and biosphere: substantial loss of species, devastating storms, significant sea level rise, and considerable displacement of communities [9].

There are external factors which could change the state of the planet that are beyond human control, for example, the output of the sun, or the shape of Earth's orbit around it [10]. However, without human influence, the stable Holocene period would be expected to continue for at least several thousand [4] to as many as 50,000 more years [11]. Human activity over the next $50-100$ years will most likely determine the state of the planet during the Anthropocene. Human activity is the only factor affecting the state of the planet that is within our control, and the Holocene is the only state of the planet in which we know humans can thrive. It seems prudent to attempt to manage human activity such that we can retain a Holocene-like state of the planet during the Anthropocene.

In 2009, Rockström et al. [5] proposed nine Planetary Boundaries, limits for Earth-system processes within which the risk of departure from a Holocene-like state is low [4] (see Table 1). Together these Boundaries define a "safe-operating-space" for humanity [4].

We have already exceeded four of the Planetary Boundaries [12]. The Planetary Boundaries show us that we are living outside the safe operating space, providing a gauge of the magnitude and urgency of the situation.

Table 1 Summary of the Planetary Boundaries (adapted from Steffen et al. [12], Table 1)

\begin{tabular}{|c|c|c|}
\hline Earth system process & Control variable & Planetary Boundary \\
\hline \multirow[t]{2}{*}{ Climate change } & Atmospheric concentration of carbon dioxide & $\leq 350 \mathrm{ppm}$ \\
\hline & Change in radiative forcing & $\leq 1 \mathrm{~W} / \mathrm{m}^{2}$ \\
\hline Biodiversity loss & Global extinction rate & $\leq 10 \mathrm{E} / \mathrm{MSY}$ \\
\hline \multirow[t]{2}{*}{ Nitrogen and phosphorus cycles } & Reactive nitrogen removed from the atmosphere & $\leq 62 \mathrm{Tg}$ \\
\hline & Phosphorous flowing into oceans & $\leq 11 \mathrm{Tg}$ \\
\hline Stratospheric ozone depletion & Stratospheric concentration of ozone measured in Dobson Units (DU) & $\leq 5 \%$ below pre-industrial levels (290 DU) \\
\hline Ocean acidification & Mean saturation state with respect to aragonite in the oceans & $\geq 80 \%$ of the pre-industrial level \\
\hline Fresh water use & Freshwater consumption & $\leq 4000 \mathrm{~km}^{3} / \mathrm{yr}$ \\
\hline Change in land-use & Area of forested land as a percentage of original forest cover & $\geq 75 \%$ \\
\hline Novel entities & NA & NA \\
\hline \multirow[t]{2}{*}{ Atmospheric aerosol loading } & Aerosol optical depth & NA \\
\hline & & Regional limit of $\leq 0.25$ \\
\hline
\end{tabular}

ppm: parts (of carbon dioxide) per million (parts of atmosphere)

Radiative forcing: the change in energy flux in the atmosphere measured in Watts per square meter of Earth's surface area $\left(\mathrm{W} / \mathrm{m}^{2}\right)$

E/MSY: extinct species per million species per year

Saturation state with respect to aragonite is an indicator of ocean acidity

Aerosol optical depth is a measure of the fraction of sunlight that is absorbed or reflected - a value of 0 indicates perfectly clear skies - a value of 1 indicates no sunlight penetration 
The problem is, how to resolve this? As shown later in this paper, the PBs as stated do not translate into their significance for community, business, and policy.

This paper sets out how to do this using three key theories that are integrated into a way of managing the Planetary Boundaries and are expanded in the main text:

1. Management theory shows that the most effective approach to managing the Earth system is likely to be a poly-scalar approach, i.e., one that can be applied in different ways, across different areas of society, and at different scales, which is coordinated by a general system of rules.

2. Accounting theory highlights the importance of standards or limits in generating change.

3. Environmental accounting theory demonstrates that the type of indicator selected is critical to the applicability to policy and behaviour applications, in this case it highlights the need to convert the PB's into pressures on the environment.

The purpose of this paper is to introduce a new paradigm - the Planetary Accounting Framework - based on the Planetary Quotas, that will help to make the Planetary Boundaries accessible and actionable. The Planetary Quotas are limits for human activity which are derived from the Planetary Boundaries. They show what is needed to return to and live within the safe operating space. The three theories set out above enable the overlap of three areas: LIMITS (Planetary Boundaries), CHANGE (poly-scalar management) and PRESSURES (environmental accounting) to create the novel concept of the Planetary Quotas (Fig. 1). These are therefore following the Sustainable Earth approach of how science, the Planetary Boundaries, can be related to both policy and community.

The Planetary Quotas form the foundations of the Planetary Accounting Framework (PAF). The PAF is a framework that shows how to apply the PQs. As shown in Fig. 2, this framework provides the platform for behavioural, policy, technological, and organisational change.

The paper begins with an overview of the three theories described above which together provide an integrated approach to change with respect to the Planetary Boundaries. We then show how the Planetary Quotas can be derived from the Planetary Boundaries with a brief description of how each of the Planetary Quotas was determined. This is followed by an overview of the PAF and how this can be used to shape policy and personal action. The paper ends with a discussion on the potential opportunities and constraints of the PAF and an overview of proposed future work on how to demonstrate the use of the PAF at different levels of human activity.

\section{Theory 1: Poly-scalar management: An approach to managing the Earth system}

The task of managing the Earth system is not straightforward. In the past, most theories on how best to manage

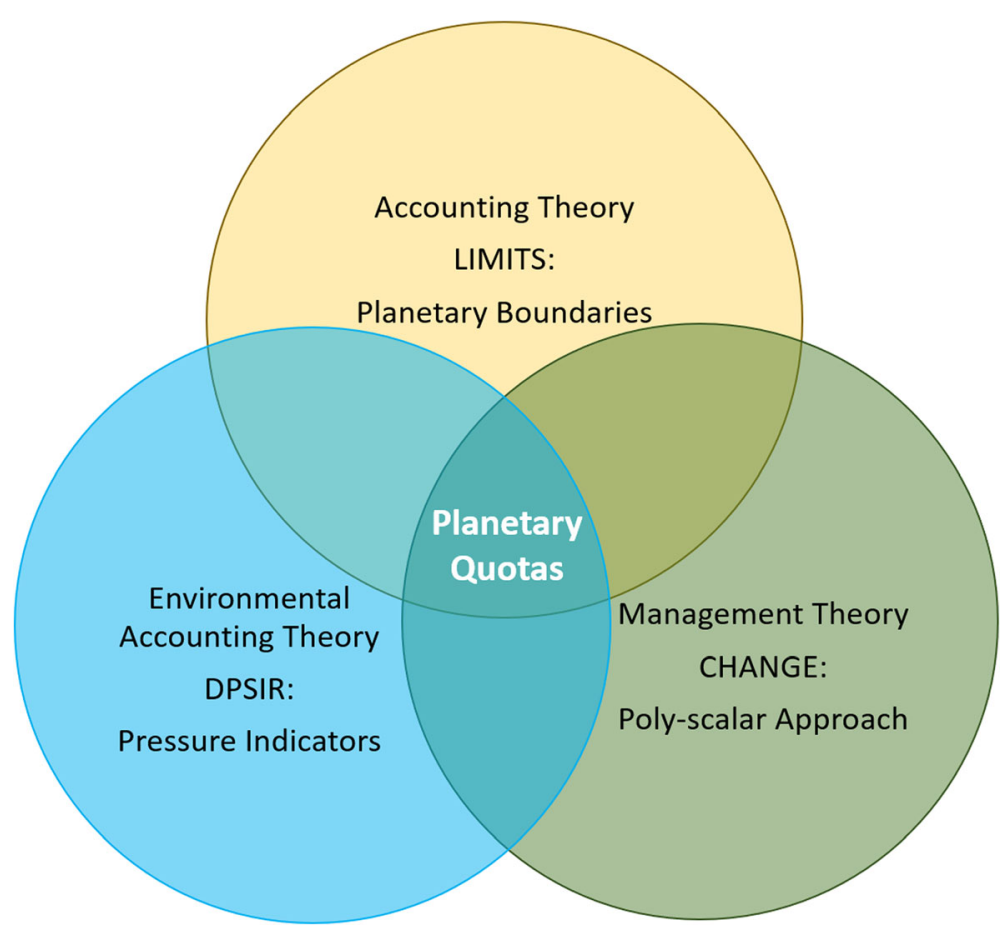

Fig. 1 The Integrated Approach to Developing the Planetary Quotas 


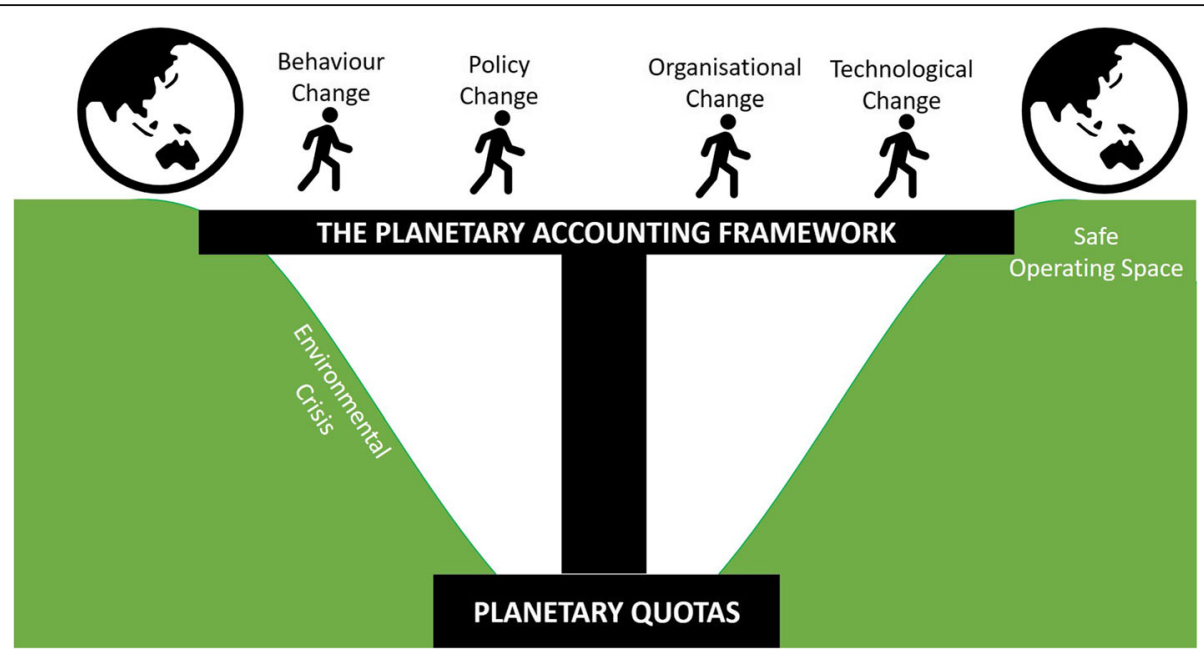

Fig. 2 The Planetary Quotas form the foundations of the Planatery Accounting Framework; a platform for change

shared resources (such as forests, fisheries, or the atmosphere) led to the conclusion that top-down governance or private management were the only effective options [1315]. These theories were based on simple game theory that used the underlying assumptions that people would always act to maximise personal gain, regardless of the greater good [13-15]. The "tragedy of the commons" is that logic will drive humans to continue to overuse resources for immediate personal gains until everyone loses [14]. These theories do not do justice to how communities actually work and how social science now understands the way human activity can change [16-20]. Cultures and communities are formed to enable broader goals to be pursued that enable more than individualistic gain. The question then is, if top-down governance and private action do not address our understanding of social science and change, what sort of global environmental management structures would be more effective?

Managing human impacts on the environment means managing human behaviour. This might mean the day to day behaviour of an individual, or the decisions made by a $\mathrm{CEO}$, or government official, or a member of the community. Studies based on observed behaviour show that there are many factors which influence decisions and that behaviour is very difficult to predict [21-23]. Lifestyle, position within a family, within society, or at work, culture, motivations, past behaviours, habits, social norms, context, and technology all play a role $[21,22,24]$. In the past, behaviour change efforts have typically been targeted at community and personal values, and social norms [24]. The findings that technology and context are key elements that influence decision making highlight the importance of infrastructure and technology and therefore governance and industry in driving pro-environmental (or other) decisions. As an example of how this can work, social media has been found to be an unintended driver for younger generations to switch from private to public transport as public transport allows them to stay connected to their peers during commuting time [25].

Nobel Prize winner Eleanor Ostrom began a movement in 1990 which used observed behaviour to dispute the validity of the theory of the commons altogether [16-20]. She and others showed through empirical evidence that the theory that individuals and small groups will not change their behaviour without external enforceable rules is far from inevitable [16, 26-33]. Community can shape the future through mutually accepted regimes of behaviour. In some instances these self-organised regimes have proved more effective than would have been feasible in the case of private action or top-down governance [18, 34]. Ostrom's theory was that the most important factors which lead to cooperative behaviour by individuals towards the environment are the trust that the behaviour will lead to long-term benefits, and the belief that the majority of others are performing the same behaviour [35]. She thus proposed a poly-centric approach for managing global environmental issues like climate change, as one which is coordinated by a general system of rules, but which enables different centres of activity to take different approaches towards the same end. The different approaches include private action, self-organisation or community-based activity, and government action at all scales. The general system of rules is included as a mechanism to impart trust in the long-term benefits of the actions, and that others are contributing to the same goal.

The science of change supports and extends the findings that different scales of activity are important and that not only community but also infrastructure and technology are key to driving change. The "magic of sustainability" is the idea that integrative solutions of community, business and government, can far exceed the sum of their parts (Fig. 3) [36]. Specifically, when long-term community 


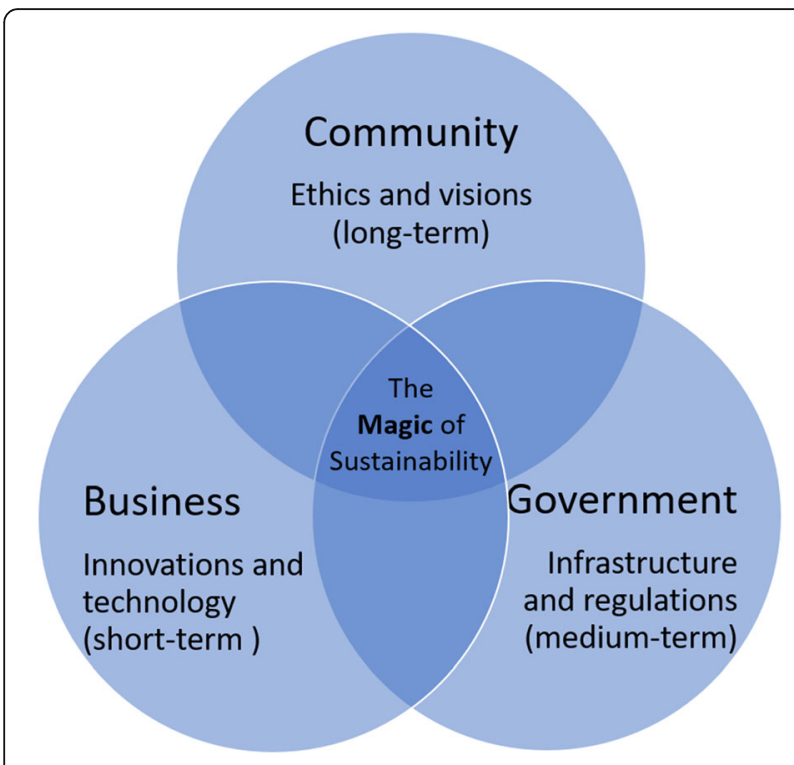

Fig. 3 The Magic of Sustainability (adapted from [36])

values and ethics overlap with mid-term government regulations and infrastructure and short-term business innovations, highly innovative and effective solutions which help to drive change can occur. Another insight from change theory is the importance of agents of change - individuals who create change in society - for example Rosa Parks - the black lady who refused to give up her seat in the white area of a bus and became a major catalyst for the movement for black rights.

Drawing from these theories, we propose that the most effective approach to change is likely to be one that can be used even more broadly than Ostrom's poly-centric approach. We propose a poly-scalar approach and define it as one which is:

integrative across different scales, sectors, and timeframes, that is not controlled by a single body, but which could be implemented through government, private ation, or self-organised management, that is coordinated by a general system of rules which have different mechanisms at different centres of activity.

Just like all management, environmental management works better when it engages people in the required activities [37, 38]. Global environmental problems are typically caused by a multitude of actions which take place at a small scale [35, 39]. Household environmental impacts (including impacts of transport and upstream impacts of goods and services acquired by households) can account for as much as $70-80 \%$ of the economy's environmental loads [40]. Given the diverse nature of the causes of global issues, global or even national policies can miss local opportunities for change $[39,41]$. People also tend to be more open to change implemented by local communities, businesses, organisations and authorities where plans have been developed with the specific community in mind, than to national level schemes [39, 41]. On the other hand, small-scale or local initiatives alone would be insufficient to manage a global problem such as climate change as many opportunities to reduce impacts rely on decisions which can only be made at a larger scale [39]. Although the literature on behaviour change shows mixed results there is powerful evidence that when design and technology are changed to focus on the appropriate scale, then the results can be positive [24, 42-44].

Benefits of a poly-scalar approach to managing the Earth system include:

- the possibility for immediate action at different scales - rather than a need to wait for global accord,

- the facilitation of widespread experimentation and learning at multiple scales - rather than the need to determine an effective approach prior to rolling out global initiatives,

- the flexibility to encompass different centres of decision-making which are formally separate - creating a bridge that is necessary to achieve change [45], and most of all

- the ability to engage people in whatever scale of activity they can focus on.

One might argue that there is already a poly-scalar approach to managing the Earth system underway. There are efforts to reduce impacts at different scales and sectors and using different approaches. What is missing from the current approach is the "general system of rules" - the common goal for this multitude of activities. Without a common goal, efforts are piecemeal. Targets for environmental initiatives range enormously, from those aiming for a very loosely defined state of "sustainability", to those working towards a circular economy, or others directing their efforts towards reducing their ecological footprint [46-49]. This can lead to a sense that environmental initiatives will make little difference to the final outcome. Moreover, many people lack confidence that others are working towards the same end.

Thus, global management theory needs to be applied to global environmental management and, in particular, the scale at which most people are engaged must be clarified. It is these poly-scalar approaches that lead to changes in design, technology, regulations, and hence behaviour [24, 44]. Such an approach would likely help to resolve the many issues inherent in managing globally shared resources and create opportunities for meaningful change. 


\section{Theory 2: Accounting theory - Creating a shared} empirical basis for different environmental issues

Accounting theory highlights the importance of measuring and monitoring assets and flows in order to make informed decisions. These decisions are strongly influenced by the limits or standards that have been set on the products or services that firms and organisations are trying to bring to market. Governments, private organisations, and households alike make informed decisions and choices based on their knowledge of the state of their assets, of incoming and outgoing cashflow and the limits or standards that are guiding their behaviour. Environmental accounting translates these insights from accounting theory to the management of environmental impacts.

Environmental Impact Assessment (EIA) is the quantification of environmental damage from human activity. Environmental accounting is the measurement and monitoring of environmental impacts over time, and often against targets that can be standards or limits required to be met. Environmental accounting is a critical element in managing the impacts of human activity on the environment. It is now possible to estimate the environmental impacts of not only past and present but also future activities with increasing levels of accuracy. Thus, decision making, planning, policy and legislation can all be made with some understanding of the corresponding environmental implications. For this reason, environmental accounting is common practice for many businesses, cities, and nations and can also be done for individuals, groups of people, or products and services.

Environmental limits or standards are not new, for example the use of environmental footprints and/or life cycle assessments to help manage the global environment is commonplace. An example is the Ecological Footprint, a measure of human use of natural capital compared to the corresponding biological capacity - or available natural capital. This framework is used to assess the impacts of most nations [50], and has been used in other smaller scale applications such as the development of an online personal impact calculator [51]. The Ecological Footprint is just one of many footprint tools. In one study of environmental footprints, 32 different footprint indicators were identified [52]. In acknowledgement that environmental footprints do not give a holistic picture of sustainability, some authors have proposed "footprint families" which are typically comprised of carbon, ecological, and water footprints [53-56].

The primary shortcoming of using environmental footprints, footprint families, and environmental accounting in general to manage impacts is that the results are rarely given in the context of science-based targets [57, 58]. Targets are often self-selected. They are typically based on a percentage improvement from a previous reporting period, sectoral commitments (for example national commitments to meet carbon targets) or using sectoral or industrial benchmarks.

There are several reasons that the lack of science-based targets is important. To begin with, incremental targets typically lead to incremental improvements (as opposed to systemic changes - i.e., change to the entire system). Incremental improvements are unlikely to be sufficient to return us to the safe operating space. Moreover, incremental improvements are criticised for their rebound effect [59-61]. The rebound effect is the phenomenon that as one area of a system improves, people feel more able to relax in other areas of the system offsetting the initial improvements, or even resulting in a worse outcome. For example, a person looking to lose weight might go for a 20 -min run. At the end of the run, she may feel that she deserves a treat to reward her efforts and eat a chocolate bar. The calories in an average chocolate bar are higher than most people would burn during a 20-min run. The net result of the run would thus be an increase in net calorie intake.

Incremental targets are less conducive to ongoing behaviour change than absolute targets [58]. They indicate that the status quo is bad, and that we must continually reduce and improve. In contrast, science-based targets present a vision of the end goal. This allows a fundamental switch in conversation from negative conversations about the status quo, to hopeful conversations about a positive future. Studies of behaviour have shown that visions of a hopeful future are more useful to generate change than scare tactics about the status quo [22]. Absolute targets do not negate the importance of incremental improvements. These are the basis of most personal and policy change [42] and can be used to implement systemic change towards an end goal.

Carbon accounting is a strand of environmental accounting where global limits are often considered. There are debates as to a "safe" level of global warming and therefore maximum allowable $\mathrm{CO}_{2}$ emissions. Nonetheless it is possible to link $\mathrm{CO}_{2}$ emissions for an activity with a global budget based on scientific knowledge.

Carbon accounting has led to widespread understanding of what is a relatively complicated scientific problem. It is used across different sectors and at different scales of activity. Individuals and communities can calculate their "carbon footprint" - the amount of $\mathrm{CO}_{2}$ released due to the activities of the individual or community. Formal greenhouse gas accounting protocols have been developed for nations, cities, and products and services eg. $[62,63] . \mathrm{CO}_{2}$ emissions have been translated into dollar values. Studies have been completed to assess the relative benefits of a carbon tax versus carbon trading. Different approaches for managing emissions and different technologies for reducing emissions or absorbing carbon from the atmosphere have been trialled in different locations and at different scales allowing for a very rapid uptake of knowledge and development. 
Carbon accounting is a remarkable example of the importance of limits. These efforts at every scale have already led to some success. Economic growth has been decoupling from greenhouse gas emissions since 2000 [64]. From 2014 to 2016 there was almost no increase in greenhouse gas emissions [65]. In 2017 emissions rose to a new peak [66]. It is disappointing that peak emissions have not yet occurred. However, trends over the last decade still appear promising. Implementing a poly-scalar approach with clearly defined global targets could help to increase the trust that efforts at every scale will make a difference to the end goal, and that others are working towards the same end.

In summary, to better manage the global environment, results of environmental impact assessments should be compared to absolute limits rather than incremental targets. We can use such an approach to drive systemic change. The PBs are absolute global limits. However, they cannot easily be connected to environmental impact assessments.

\section{Theory 3: The DPSIR environmental accounting framework and accessible indicators}

Several authors have highlighted the opportunity for the Planetary Boundaries to reform environmental governance at multiple scales e.g. [45, 58, 67]. Several efforts have already been made to use the PBs for environmental accounting at different scales. For example, there have been several attempts to link the PBs to existing environmental assessment frameworks including footprint tools and life-cycle assessments [68, 69]. National targets have been developed based on the PBs for Switzerland, Sweden, and South Africa, and regional targets for the European Union, and environmental accounting against these targets has begun [70-72]. However the work is disjointed and incomplete.

The PBs as designed by the planetary scientists who first proposed them, were not intended to be disaggregated or scaled [12]. The purpose of the PBs was to provide a clear snap shot of the status quo of critical Earth-system processes based on how these systems are measured globally. They do not define limits for human activity.

Each of the works adapting or scaling the PBs and using these for environmental accounting has severe limitations. To begin with, none of them correspond to the PB for climate change. There is a wide variation in the indicators selected for biosphere integrity. So much so that it would be very difficult to contrast and compare any of the limits with one another or with the original PB. More importantly perhaps, none of the adaptations are suitable for use beyond the application for which they were intended. The national indicators developed would be difficult to apply to city or regional levels or to translate into business targets. This means that even within that nation, different levels of activity would be working towards different targets. The level of effort that has gone into each of the adaptations is high. It would not be practical to repeat such an involved process for every intended use. None of the adaptations are suitable for a poly-scalar approach.

The Driver-Pressure-State-Impact-Response (DPSIR) framework is used below to show why the Boundaries cannot easily be scaled or used in environmental accounting as they are. In response to the vast number of environmental indicators developed for environmental impact assessments, a system to categorise these was adopted by the European Environment Agency - the DPSIR framework, detailed in Fig. 4 [70, 72, 73]. The DPSIR framework not only enables the classification and therefore better understanding of indicators, it can also be used to translate indicators from one category to another as there is a causal relationship between each category [73]:

- Driver indicators describe human needs. Some examples of Driver indicators include kilowatt hours of electricity, kilometres travelled, or litres of fuel for transport.

- Pressures which result from drivers are flows to the environment. One Pressure indicator resulting from the Driver indicators listed is $\mathrm{CO}_{2}$ emissions.

- State indicators describe the environment. State indicators provide a snapshot of the status quo. Comparing the current State of a given ecosystem to a previous State allows us to understand the influence of human activity on the environment. For example, the change of the State indicator which corresponds to $\mathrm{CO}_{2}$ emissions - the concentration of $\mathrm{CO}_{2}$ in the atmosphere - has allowed us to understand the ramifications of emitting $\mathrm{CO}_{2}$. It is this sort of indicator that is commonly used in State of the Environment Reporting.

- Impact indicators describe the results of changing environmental States. For example, one of the Impacts of the increased concentration of $\mathrm{CO}_{2}$ in the atmosphere is an increase in average global temperature. Another Impact is species extinctions.

- Response is not a category of indicator. Rather it is included in the framework to show that different types of responses can be linked to different categories of indicators (see Fig. 4)

Human activity directly influences Pressures and Drivers and only indirectly influences States and Impacts. This means that State and Impact indicators are useful to describe the status quo, and to monitor change over time. However, they cannot be easily related to human activity. There is no straightforward way to divide the responsibility for the concentration of $\mathrm{CO}_{2}$ in 


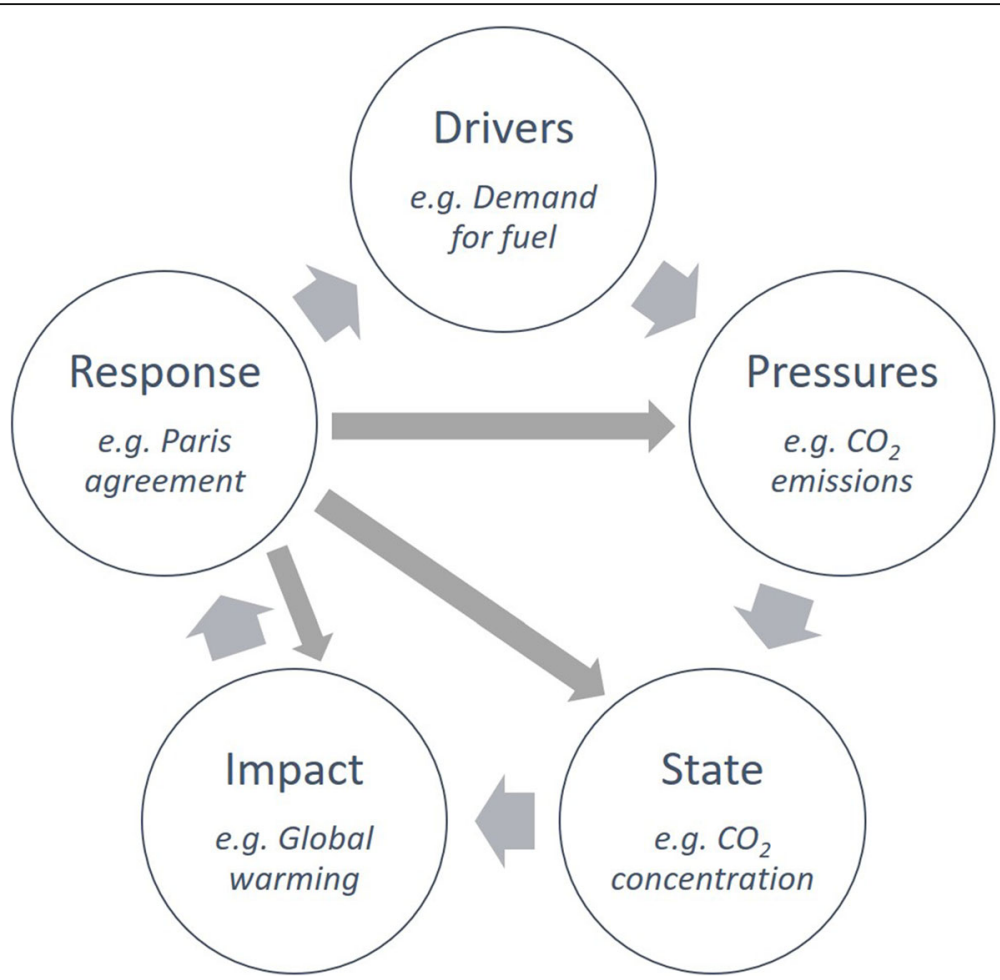

Fig. 4 The Driver Pressure State Impact Response Framework

the atmosphere between different nations, cities, regions, or individuals unless a different indicator can be found that is easily scaled. Nor can one directly compare specific human activities to the global average temperature. An individual deciding whether to take the car or the train to work, or a local government deciding whether to proceed with certain infrastructure - neither could begin to estimate the impacts of these decisions on the atmospheric concentration of $\mathrm{CO}_{2}$. It is only when these indicators are translated to the Pressure indicator $-\mathrm{CO}_{2}$ emissions, that it becomes possible to begin to allocate this global budget between nations, cities, or any other level.

Table 2 shows how each of the Planetary Boundary control variables fits into different DPSIR framework categories. There are three Pressure indicators, five State indicators, and one Impact indicator - i.e., the indicators do not all belong to a single category. This explains the reason why the Planetary Boundaries have not easily been translated into action.

For a poly-scalar approach to be applied to the Planetary Boundaries, a new set of Pressure indicators, derived from the PBs, is needed. We have called these the Planetary Quotas (PQs). Each of these are set out below. Once derived the PQ's can then enable us to link human activity to key global limits through the Planetary Accounting Framework.

\section{Developing the Planetary Quotas}

Some authors have identified the opportunity to use the DPSIR framework to determine a causal relationship between human activity and the Planetary Boundaries [70, $72,74]$. Two of the national adaptations of the PBs use a methodology based on the DPSIR framework [70, 72]. However, neither study applied this approach across all of the PBs. Nor did either propose a set of indicators that were uniformly of the Pressure category.

The Planetary Boundaries are presented as distinct control variables with explicit limits. This is by design to make them easily communicable [12]. In reality, there is a high level of interconnectivity between the PBs. For example, almost every PB affects biosphere integrity. Exceeding one PB affects our ability to remain within others.

For the PQs to be a robust translation of the PBs, this interconnectivity must be carried over to the PQs. It would not be suitable to translate each PB to a PQ without consideration of all of the other PBs and PQs. To manage this, the method used was to first translate each of the PBs into a list of critical pressures based on the scientific literature (see Additional file 1: Table S1), and then from this list, PQs were developed.

There are many pressures which only have minor contributions towards the PBs, so an exclusion protocol was applied for pressures which contribute less than $1 \%$ towards current global impacts. Excluding 
Table 2 Driver-Pressure-State-Impact-Response (DPSIR) classification of the Planetary Boundary control variables

\begin{tabular}{lll}
\hline Earth system process & Planetary Boundary Control variable & DPSIR Category \\
\hline Climate change & Atmospheric concentration of $\mathrm{CO}_{2}$ & State \\
& Change in radiative forcing & State \\
Biodiversity loss & Extinction rate & Impact \\
Nitrogen and phosphorus cycle & $\mathrm{N}_{2}$ removed from the atmosphere & Pressure \\
& P flowing into oceans & Pressure \\
Stratospheric ozone depletion & Atmospheric concentration of ozone & State \\
Ocean acidification & Mean saturation state of aragonite in the oceans & State \\
Fresh water use & Freshwater consumption & Pressure \\
Change in land-use & Percentage of land cover converted to cropland & State \\
Novel entities & NA & NA \\
Atmospheric aerosol loading & Aerosol optical depth & State \\
\hline
\end{tabular}

minor impacts is common practise in environmental assessment protocols as a means to simplify the process with minimal effect on the results [75]. In total, thirty-two critical pressure were found. These were then analysed to determine which of the pressures could be grouped, and to find appropriate Pressure indicators to assess these with. The result was ten Pressure indicators which formed the basis of the PQ development.

Each of the PQ indicators found corresponds to one or more of the critical pressures and therefore one or more $\mathrm{PB}(\mathrm{s})$. The $\mathrm{PQ}$ limits were thus determined by assessing each of the corresponding PBs and selecting the most stringent limit.

The translation of the PBs to pressures and then to PQs is shown in Fig. 5. The direct relationship between the PBs and PQs is shown in Fig. 6. Two of the Planetary Boundaries have previously been identified as "core boundaries" for their high level of interconnectivity Climate Change and Biosphere Integrity [12]. Each of these correspond to more than half of the Planetary Quotas (see Fig. 6).

The PQs are summarised in Table 3. The scientific basis for each PQ is described briefly below. More detailed descriptions are included in the Supplementary Information where needed.

\section{A quota for carbon dioxide emissions}

Carbon dioxide $\left(\mathrm{CO}_{2}\right)$ emissions is a critical pressure which affects several of the PBs (see Additional file 1). The PB that translates to the most stringent PQ for $\mathrm{CO}_{2}$ is the $\mathrm{PB}$ for the concentration of $\mathrm{CO}_{2}$ in the atmosphere of $\leq 350 \mathrm{ppm}$. The concentration of $\mathrm{CO}_{2}$ in the atmosphere is currently $\geq 400 \mathrm{ppm}$, i.e., this $\mathrm{PB}$ has been exceeded. No other pressures were grouped with $\mathrm{CO}_{2}$ for this $\mathrm{PQ}$ because the only way to meet the $\mathrm{PB}$ for $\mathrm{CO}_{2}$ concentration is through the uptake of $\mathrm{CO}_{2}$ from the atmosphere. The indicator selected for this $P Q$ is thus net carbon dioxide emissions; net because to return to $350 \mathrm{ppm}$ will require uptake of $\mathrm{CO}_{2}$ from the atmosphere.

There are several pathways for rapid decarbonisation in the literature e.g., [76-79]. However, only one of these shows the concentration of $\mathrm{CO}_{2}$ in the atmosphere as returning to $350 \mathrm{ppm}$ within this century [76]. This pathway entails rapid reductions in $\mathrm{CO}_{2}$ emissions of $15 \%$ per annum starting no later than 2020 followed by net $\mathrm{CO}_{2}$ uptake from 2030 to 2080, and net zero emissions thereafter. The proposed uptake of $\mathrm{CO}_{2}$ is approximately constant at 7.3Gt/yr. from 2050 to 2080. Thus, the limit is set as net carbon dioxide emissions $\leq-7.3 \mathrm{Gt}$ / yr (see Additional file 1 for further detail).

All of the PQs should be reassessed over time. This is particularly so for the PQ for $\mathrm{CO}_{2}$ emissions. If $15 \%$ reductions do not start by 2020 this PQ will need to be amended at this time. Any delay will mean substantially higher reductions will be required.

\section{A quota for methane and nitrous oxide emissions}

Methane and nitrous oxide emissions (hence forth referred to as Me-NO) are the only two long-lived greenhouse gases in the list of critical pressures (Additional file 2) which can have positive limits whilst respecting the PBs. As such, these pressures have been grouped under the PQ for Me-NO. It is common practice to assess impacts of greenhouse gases (GHGs) in terms of the amount of $\mathrm{CO}_{2}$ emissions that would result in the same amount of global warming - equivalent $\mathrm{CO}_{2}$ $\left(\mathrm{CO}_{2} \mathrm{e}\right)$, this is the unit that has been selected here.

The PB most affected by Me-NO emissions is the PB for radiative forcing, i.e., a change in radiative forcing since preindustrial forcing $\leq \pm 1 \mathrm{~W} / \mathrm{m}^{2}$. However, there are too many different factors which influence radiative forcing (e.g., greenhouse gas emissions, albedo (Earth's reflectivity), and aerosol emissions) to use this $\mathrm{PB}$ to derive specific limits for $\mathrm{Me}-\mathrm{NO}$. 


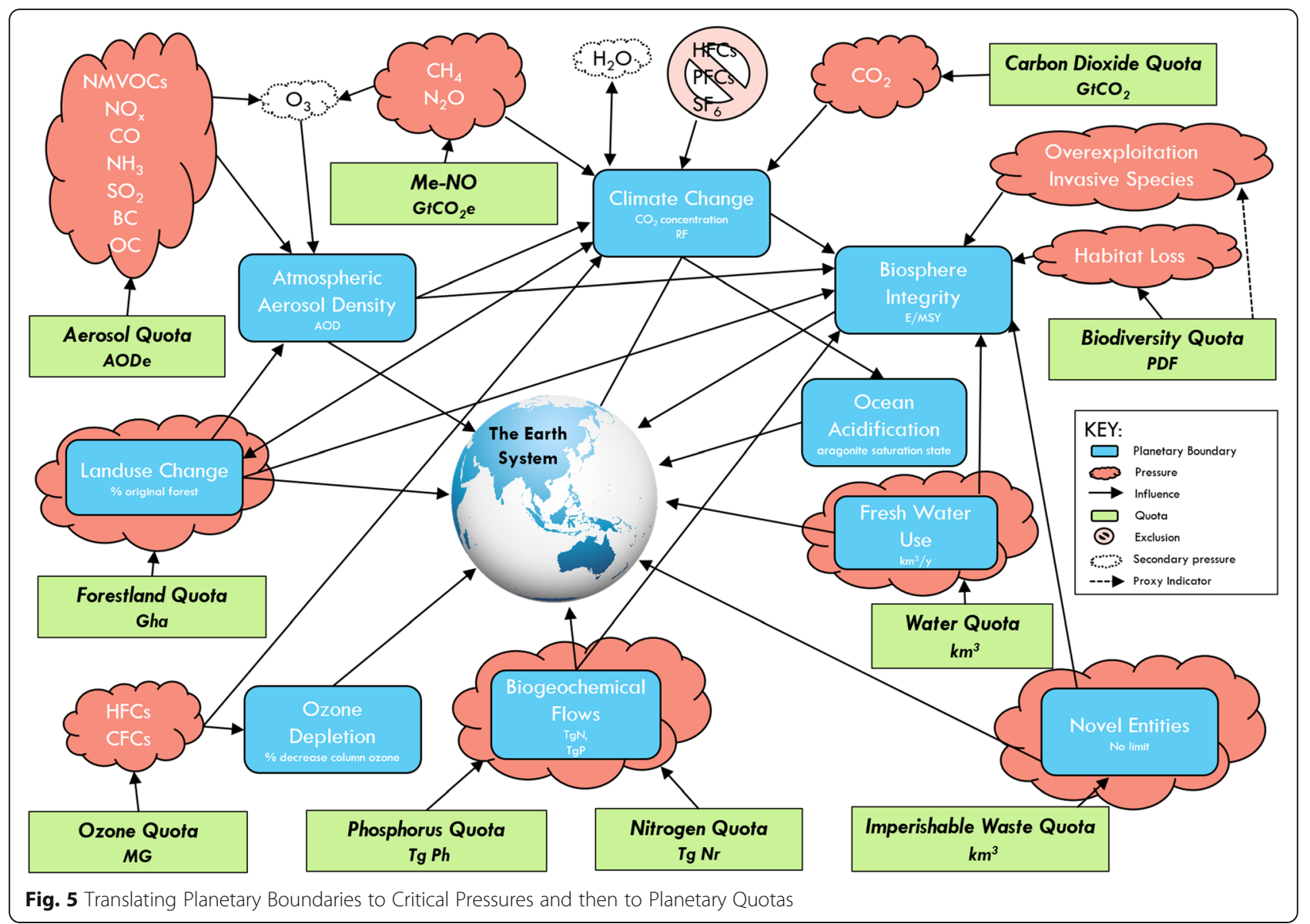

The IPCC has identified several emissions pathways for the future. Even the most stringent of these, RCP2.6, does not meet the $\mathrm{PB}$ for radiative forcing this century. However, the 2100 targets for Me-NO under RCP2.6 have been derived on the basis of optimal food production with minimal emissions and minimal land use. It can be shown that these targets are sufficient to respect the $\mathrm{PB}$ for radiative forcing (see Additional file 1).

Nitrous oxide is also an ozone depleting substance so the limits for nitrous oxide emissions must also be considered in the context of the PB for ozone depletion. It can be shown that the RCP2.6 2100 target is unlikely to prevent the $\mathrm{PB}$ for ozone depletion from being respected (see Additional file 1).

Thus, the RCP2.6 2100 targets have been used as the basis of the PQ for Me-NO. The limit is gross Me-NO emissions $\leq 5.4 \mathrm{GtCO}_{2} \mathrm{e} / \mathrm{yr}$.

\section{A quota for forestland}

There are several critical pressures which relate to land use and land-use change (see Additional file 1). Forestland is of particular significance however, because it plays an integral role in the carbon, water, and nitrogen cycles. Forests also provide habitat for over $80 \%$ of terrestrial species [80]. Forestland function cannot be offset by other land types. As such, there are two PQs pertaining to land use, the PQ for forestland (discussed here) and the PQ for biodiversity which addresses land use more broadly, but with specific consideration for the impacts of land use on biodiversity (see section "A Quota for Water").

The decarbonisation pathway used to determine the limit for $\mathrm{CO}_{2}$ emissions [76] (see section "A Quota for Carbon Dioxide Emissions") and the PB limit for land use of global forest land $\geq 75 \%$ of original forest area [12] both suggest that approximately $0.9 \mathrm{Gha}$ of reforestation will be needed by the end of this century (see Additional file 1). Applying this linearly over the remainder of the century gives a PQ for forestland of deforestation $\leq-11 \mathrm{Mha} / \mathrm{yr}$.

\section{A quota for ozone depleting substances}

The hole in the ozone layer is an example of how significant damage from human activity can be, and of how effective global action can be in restoring planetary health. The Montreal Protocol is a universally ratified agreement to phase out the production and use of ozone depleting substances. It has been predicted that if the 


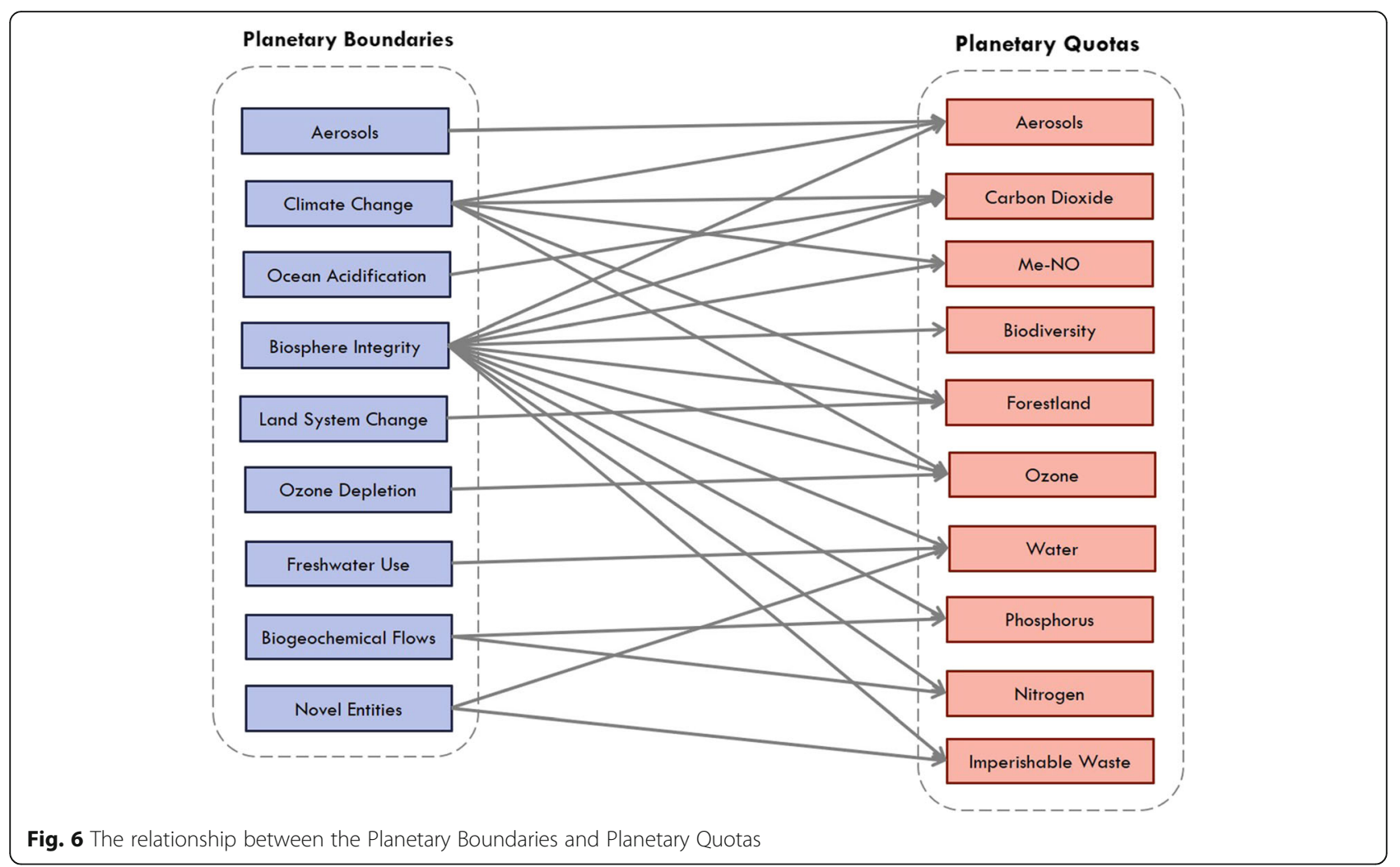

Protocol is respected, i.e., that Montreal gases are phased out, the Planetary Boundary for ozone depletion will be too [5]. Not all ozone depleting substances are included under the Protocol, the notable exception being nitrous oxide. However, provided the PQ for $\mathrm{Me}-\mathrm{NO}$ is respected, it is unlikely that nitrous oxide emissions would cause the PB for ozone depletion to be exceeded (see Additional file 1).

Montreal gases have different effects on ozone but can be collectively measured in the unit ozone depleting potential kilograms (ODPkg), which is a measure of the relative impact on the ozone of different gases compared to a benchmark substance. The PQ for ozone is set at Montreal gas emissions $\approx 0$ ODP $\mathrm{kg}$ (see Additional file 1 for more detail).

\section{A quota for aerosols}

Aerosols are small particles suspended in the air. They can be released directly, or form as a result of emissions of precursor gases. There was not previously a Pressure indicator for the collective measurement of aerosols and precursors that could be related to the state of the atmosphere.

Aerosol optical depth (AOD) is an optical measure of the concentration of particles in the air. It is the ratio of incident light either scattered or absorbed by airborne particles in a vertical column of air [81]. An AOD of 1 indicates that no light can pass. An AOD of 0 indicates perfectly clear skies.

Meyer and Ryberg have proposed a new unit, equivalent aerosol optical depth (AODe). ${ }^{1}$ Characterisation factors have previously been proposed to link annual mass of emissions of aerosols and precursors to globally averaged change in AOD. Building on this approach, Meyer and Ryberg used these factors to link emissions from an activity to global average AOD and thus determine the AOD equivalent (AODe). This should not be confused with an estimation of actual change in AOD. Such an estimation would be highly inaccurate because of variations to local conditions and the interactions between different aerosols and precursors. AODe provides a link between emissions, the Pressure indicator, and the resultant optical depth, the State indicator. It is thus an appropriate indicator for the PQ for aerosols.

The World Health Organisation suggests that no level of particulate concentration is safe for human health, suggesting an AODe of zero would be the most appropriate. However, the impacts of aerosols on global warming must also be considered. Aerosols have a net cooling effect in the atmosphere and are believed to have substantially dampened the warming effects experienced so far because of greenhouse gas emissions. Eliminating them entirely could lead to accelerated warming which could be more harmful to humanity than a small 
Table 3 The Planetary Quotas

\begin{tabular}{|c|c|c|}
\hline $\begin{array}{l}\text { Planetary } \\
\text { Quota }\end{array}$ & $\begin{array}{l}\text { Control Variable } \\
\text { and Global Limit }\end{array}$ & $\begin{array}{l}\text { Description of } \\
\text { Control Variable }\end{array}$ \\
\hline $\begin{array}{l}\text { Carbon } \\
\text { dioxide }\end{array}$ & $\begin{array}{l}\text { Net } \mathrm{CO}_{2} \text { emissions } \\
\leq-7.3 \mathrm{GtCO}_{2} / \mathrm{yr}\end{array}$ & $\begin{array}{l}\text { Net } \mathrm{CO}_{2} \text { emissions including } \\
\text { land use and land-use change } \\
\text { emissions. }\end{array}$ \\
\hline Me-NO & $\begin{array}{l}\text { Me-NO emissions } \\
\leq 5.4 \mathrm{GtCO}_{2} \mathrm{e} / \mathrm{yr}\end{array}$ & $\begin{array}{l}\text { Total warming potential of } \\
\text { methane and nitrous oxide } \\
\text { emissions expressed in terms } \\
\text { of equivalent } \mathrm{CO}_{2} \text { emissions } \\
\left(\mathrm{CO}_{2} \mathrm{e}\right) \text {. }\end{array}$ \\
\hline Forestland & $\begin{array}{l}\text { Deforestation } \\
\leq-11 \mathrm{Mha} / \mathrm{yr}\end{array}$ & Net deforested land area. \\
\hline Aerosols & $0.04 \leq \mathrm{AODe}^{\mathrm{a}} \leq 0.1$ & $\begin{array}{l}\text { Emissions of aerosols and } \\
\text { precursor gases expressed } \\
\text { in terms of equivalent } \\
\text { aerosol optical depth } \\
\text { (AODe) }\end{array}$ \\
\hline Ozone & $\begin{array}{l}\text { Montreal gas emissions } \\
\approx \leq 0 \mathrm{ODPkgs} / \mathrm{yr}\end{array}$ & $\begin{array}{l}\text { Emission of gases controlled } \\
\text { or due to be controlled under } \\
\text { the Montreal Protocol in terms } \\
\text { of ozone depleting potential } \\
\text { weighted kilograms (ODPkg) }\end{array}$ \\
\hline Nitrogen & $\begin{array}{l}\text { Net nitrogen released } \\
\text { to the environment } \\
\leq 62 \mathrm{Tg} / \mathrm{yr}\end{array}$ & $\begin{array}{l}\text { Net reactive nitrogen released } \\
\text { to the environment. }\end{array}$ \\
\hline Phosphorous & $\begin{array}{l}\text { Net phosphorus } \\
\text { released to the } \\
\text { environment } \leq 11 \mathrm{Tg} / \mathrm{yr}\end{array}$ & $\begin{array}{l}\text { Net phosphorus released to } \\
\text { the environment. }\end{array}$ \\
\hline Water & $\begin{array}{l}\text { Net water consumption } \\
\leq 8500 \mathrm{~km}^{3} / \mathrm{yr}\end{array}$ & $\begin{array}{l}\text { Net green, blue and grey } \\
\text { water consumption }\end{array}$ \\
\hline Biodiversity & $\begin{array}{l}\text { Percentage } \\
\text { disappearing fraction } \\
\text { of species } \leq 1 \mathrm{E}-4 / \mathrm{yr}\end{array}$ & $\begin{array}{l}\text { Net percentage disappearing } \\
\text { fraction of species due to land } \\
\text { occupation and transformation }\end{array}$ \\
\hline Novel entities & $\begin{array}{l}\text { Net imperishable } \\
\text { waste } \leq 0 \mathrm{~kg}\end{array}$ & $\begin{array}{l}\text { Imperishable waste released } \\
\text { to the environment less } \\
\text { imperishable waste removed } \\
\text { from the environment. }\end{array}$ \\
\hline
\end{tabular}

aODe: Aerosol Optical Depth equivalent (see Section "A Quota for Aerosols") bODPkg: Ozone Depleting Potential kilograms (see Section "A Quota for Ozone Depleting Substances")

amount of particulate concentration remaining in the atmosphere.

The $\mathrm{PB}$ for radiative forcing is linked to the $\mathrm{PQs}$ for $\mathrm{CO}_{2}, \mathrm{Me}-\mathrm{NO}$, forestland, Montreal gases, and aerosols. Using the previously discussed PQs, and the PB for radiative forcing, a range of acceptable AODe levels can be determined as $0.05 \leq \mathrm{AODe} \leq 0.13$. The $\mathrm{WHO}$ guidelines for maximum particles in the atmosphere can be translated to an upper limit of AODe $\leq 0.1$, which is in line with the PB for aerosols. Thus, the PQ for aerosols is $0.04 \leq \mathrm{AODe}$ $\leq 0.1$ (see Additional file 1 for additional details).

\section{A quota for nitrogen}

Reactive nitrogen is necessary to grow food. However, the overuse of nitrogen can cause algal blooms and create anaerobic dead zones in rivers, lakes, and oceans. The PB for nitrogen is $62 \mathrm{TgN} / \mathrm{yr}$. of intentionally fixated nitrogen.
This is a Pressure indicator, yet it cannot easily be compared to human activity. Further, it is not the fixation of nitrogen that causes algal blooms. Rather, it is the loss of nitrogen to the environment. Thus, the indicator for the PQ for nitrogen is net nitrogen lost to the environment. This includes virtual nitrogen that has been lost to the environment during the production of food and products, and the nitrogen released in excreta, less any nitrogen recovered, for example through the denitrification of waste water.

The PB for nitrogen was set on the basis of estimates for critical environmental limits for of nitrogen in surface runoff [82]. This basis is also suitable for the PQ indicator. As such, the PQ for nitrogen is net nitrogen lost to the environment $\leq 62 \mathrm{TgN} / \mathrm{yr}$ (see Additional file 1 for additional details).

\section{A quota for phosphorus}

Like nitrogen, phosphorus is also necessary to grow food but can cause algal blooms if used excessively. The PB for phosphorus is a flow of no more than $11 \mathrm{TgP} / \mathrm{yr}$. from freshwater systems to the ocean. The limit is set at a point where the risk of a global anoxic ocean event is considered low [4].

This indicator is a Pressure indicator but not one that is easily comparable to human activity. A more accessible indicator has been selected for the PQ for phosphorus - net phosphorous released to the environment. It can be assumed that most phosphorus released to the environment will eventually make its way to the oceans. As such, the PQ for phosphorus is set at the same level as the $\mathrm{PB}$ for phosphourus i.e., net phosphorous released to the environment $\leq 11 \mathrm{TgP} / \mathrm{yr}$.

\section{A quota for water}

Water availability varies significantly across the globe. In some areas it is plentiful. In others, it is very scarce. It is not feasible to transport water over long distances. For this reason, the concept of a global limit for water is debated. However, only a small fraction of total water consumption is direct consumption of local water. The far larger percentage of water consumed is "virtual water", i.e., water used in the production of goods. Unlike water in its useable form, virtual water is traded globally. Approximately $40 \%$ of Europe's water footprint is imported. We argue that the global distribution of water through trade justifies a global limit for water.

The PB for water consumption is for gross blue water consumption $\leq 4000 \mathrm{~km}^{3}$. Blue water refers to fresh surface water and groundwater, i.e., the water found in freshwater lakes, rivers and aquifers. Precipitation on land is classified as green water. The authors of the PBs acknowledge that green water is a scarce resource and should be considered within the PBs. However, because 
of the difficulty in defining a green water boundary they used blue water as a preliminary proxy indicator [5, 12].

Blue water consumption is not a suitable proxy for use in environmental accounting as this would imply that the use of green water, for example rain fed crops, has no impact. On the contrary, human appropriation of green water can result in loss of soil moisture and a decline in moisture feedback of vapour flows [5]. Further, $74 \%$ of the global average water footprint of production between 1996 and 2005 was from green water [83].

Gross water consumption is also a poor proxy indicator for environmental accounting purposes as it ignores the end state of the water. Net water consumption and the inclusion of grey water, i.e., the amount of water required to assimilate pollutants in water, gives a more holistic indicator of human appropriation of the water cycle.

The indicator for the PQ for water is therefore net blue, green, and grey water. There is no clearly defined global limit for this indicator. However, on the basis that more than $30 \%$ of major groundwater sources are currently being depleted, it is argued by some that we are already at, if not beyond the limit [84]. The PQ for water is thus $\leq 8500 \mathrm{~km}^{3}$ based on the current global water footprint (which includes blue, green, and grey water consumption) [84] (see Additional file 1 for further detail).

Some water accounting experts believe that a weighted water footprint would better account for regionality [85] (see section "The Planetary Quotas in Context" for a discussion on regionality and the weighted water footprint).

\section{A quota for biodiversity}

There are five key drivers of biodiversity loss [5, 52, 86-88]:

a) climate change - shifting habitat to an extent that it is no longer suitable for the threatened species;

b) pollution that affects the health of species;

c) overexploitation of species, especially due to fishing and hunting but also overuse of ecosystem services leading to aforementioned habitat loss;

d) spread of invasive species or genes outcompeting endogenous species; and

e) habitat loss, fragmentation or change, especially due to agriculture, large-scale forestry, and human infrastructure.

Climate change is considered under the PQs for $\mathrm{CO}_{2}$, Me-NO, forestland, Montreal gases, and aerosols. Pollution is considered under the PQs for aerosols, water, nitrogen, phosphorus, and novel entities. The remaining three drivers have complex and diverse pathways. A study by the Convention on Biodiversity CBD [89] summarised the primary drivers for over 500 invasive species and found over 40 drivers ranging from purposeful release for measures such as erosion control, and hunting, to escape of pets, contamination of international trade objects, and stowaways on container ships. At this time, no Pressure indicator exists to account for all three of these drivers.

Land-use change is considered by many to be the greatest threat to biodiversity [88, 90-95]. For this reason, the use of land-based indicators as a proxy for biodiversity is common practise. The Ecological Footprint is often used as a proxy indicator for biodiversity health on the basis that it is a measure of how much biologically productive land is used by humans. Some level of overexploitation of marine and terrestrial species is taken into account in this metric [86]. The problem with using this indicator is that there is little consensus as to an appropriate limit [46, 86, 91, 96-98].

In a UNEP report on life cycle indicators, the need for a scalable indicator to assess the land use related impacts on biodiversity was identified and a new indicator proposed [99]. The indicator is called the percentage disappeared fraction (PDF) of species. This indicator is similar to the Ecological Footprint in that different types of land are weighted in terms of relative impacts. However, it has been specifically developed as a proxy indicator for biodiversity loss. Moreover, the unit can easily be equated to the Planetary Boundary for biosphere integrity extinction rate - as both are expressed in terms of the percentage of extinct (or disappeared) species. The difference between the PDF and extinction rate is in their determination. Extinction rate is determined through observation - it is an Impact indicator. In contrast, PDF is estimated using land use data - thus a Pressure indicator. The PQ for biodiversity it thus PDF $\leq 1 \mathrm{E}-4 / \mathrm{yr}$.

The purpose of the UNEP report was to propose indicators that allow better consistency in the development and communication of green products. This differs from the purpose of the Quotas in that the Quotas are intended to be the basis of a global Planetary Accounting Framework that can be used for any scale of human activity. In the instance of the UNEP report, there is little need to account for positive land transformation. As such, all of the "correction factors" - numbers used to convert land transformation to percentage disappeared fraction - are positive (i.e. they lead to biodiversity loss). Further work will be required to determine correction factors for positive transformation which results in biodiversity gains.

\section{A quota for novel entities}

There is no indicator or limit proposed for novel entities in the PB framework. However, they are included as a $\mathrm{PB}$ to give an indication of their importance to planetary health. The authors of the PB framework define novel entities as new substances, new forms of existing substances and modified life-forms that have the potential for unwanted geophysical and/or biological effects. 
The environmental impacts from novel entities most often occur because of the disposal of these. The release of toxins into waterways. The disposal of waste to landfill. The disposal of plastic into oceans. As such, we propose the indicator net imperishable waste measured in kilograms to account for the wide variety of novel entities.

There is no specific limit proposed in the literature for this metric. However, there is evidence that we are beyond the limit. For example, 83\% of tap water samples from 12 nations have been found to be contaminated with plastic [100]; methane from landfills and wastes contributes approximately $23 \%$ of global methane emissions [101]; most fish which are high in the food chain now contain high levels of heavy metals such as mercury [102]. The PQ for novel entities is therefore net imperishable waste $\approx 0 \mathrm{~kg} / \mathrm{yr}$.

The choice of net rather than gross waste is to allow environmental impact assessment results to show negative imperishable waste disposal. In this way, activities such as landfill mining which result in a net removal could be encouraged. Value could be assigned to such activities to allow for trading of impacts within a global cap. Further work should be undertaken to determine whether a zero limit is sufficient.

\section{The Planetary Accounting Framework}

The Planetary Quotas form the foundations for the new Planetary Accounting Framework (PAF). The PAF shows how the PQs can be used in a poly-scalar approach to manage global impacts. It can be used to assess the impacts of different scales of human activity against planetary limits. Figure 7 shows how the Framework can work for different scales and purposes.

The left-hand side shows the inputs and the right-hand side shows the outputs. The inputs are both top-down - scaling the Planetary Quotas to the scale of assessment - and bottom up - using environmental impact assessment methods to estimate impacts in each environmental activity.

\section{Bottom up}

Prior to completing an environmental impact assessment, the scope, i.e., the inclusions and exclusions, must be

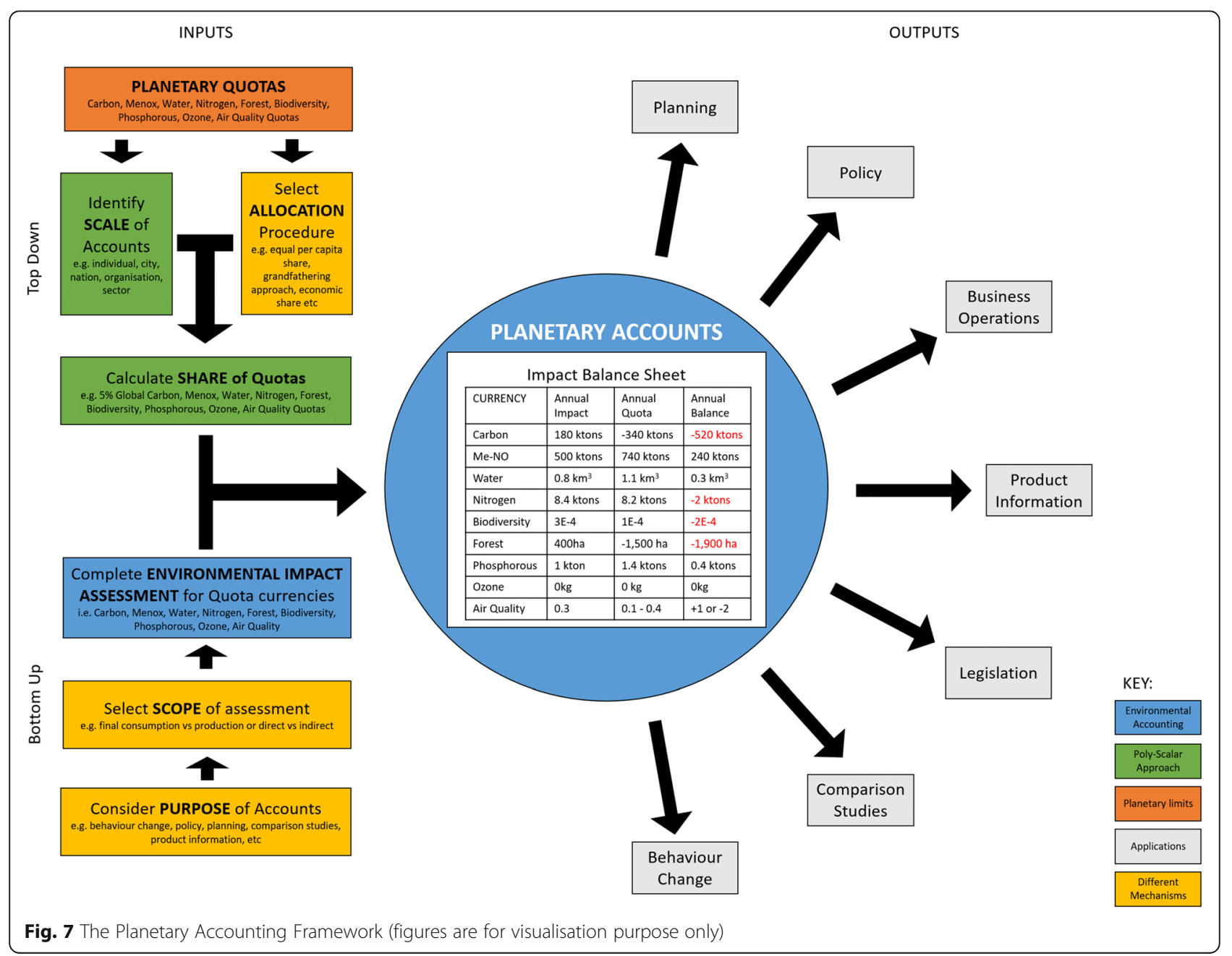


determined. The scope of assessment will depend on the purpose. For example, if a city government was looking to compare impacts per capita of their population with another city's population it would likely be most appropriate to assess the final consumption of its inhabitants. In contrast, if the same city was trying to prioritise infrastructure and development it might be more appropriate to assess the impacts that occur within the city itself.

The inclusions and exclusions can make a very big difference to the results. For example, in Sweden the emissions produced within the Swedish borders has reduced from $72.7 \mathrm{MtCO}_{\mathrm{e}}$ in 1990 to $66.2 \mathrm{MtCO}_{2}$ in 2010 (Swedish EPA, 2012a). However, when they calculated the emissions corresponding to the consumption of the inhabitants of Sweden, the results were $76 \mathrm{MtCO}_{2}$ in 1990 and $95 \mathrm{MtCO}_{2}$ in 2010 (Swedish EPA, 2010). One set of accounts showed a decrease in emissions while the other showed an increase. Both sets of accounts provide information that is useful, but for different purposes.

Once the scope is defined, an environmental impact assessment can then be done to determine the impacts in each of the PQ currencies using standard environmental assessment methods.

\section{Top down}

To translate the global PQs to the scale of the planetary accounts (e.g., national, city, business), an allocation procedure will need to be determined. The Planetary Quotas help to resolve the mathematics of apportioning shares of the operating space to different scales of human activity. However, distributing Earth's finite resources among past, present, and future generation is not simply a question of mathematics. It is question of ethics, morals, and beliefs.

For the PAF to form the general system of rules for a poly-scalar approach to managing global impacts it should have different mechanisms at different scales and for different purposes. For such a flexible approach, allocation procedures also need to have a high degree of flexibility. An allocation procedure for PQs for the basis of self-organised initiatives is likely to be self-selected. Global negotiations for national commitments to PQs are likely to be heavily influenced by politics. Private organisations may agree sectoral approaches to allocating Quotas, may self-select allocation procedures for Quotas as part of an internal sustainability strategy, or may be allocated Quotas by local authorities or company managers. The PAF does not attempt to resolve the question of which allocation procedure(s) is most suitable. Rather, it has the flexibility to allow different types of allocation procedure to be applied as needed.

The Quotas as shown in Table 3 are global limits. Each Quota has been designed to be scalable, however, not every Quota is divisible. The Carbon Quota is an example of a Quota that is divisible - i.e., the global Quota of $-7.3 \mathrm{GtCO} 2 / \mathrm{yr}$. could be divided by the global population (say 7.5 billion) to get an equal per capita share of $\approx-1 \mathrm{tCO} 2 / \mathrm{yr}$. per person.

In contrast, the PQ for aerosols is not divisible. The unit (aerosol optical depth equivalent) applies directly at any scale. Thus, both the global Planetary Quota, is the same as (for example) any individual's Planetary Quota. Table 4 shows which Quotas are divisible and which are not.

\section{The impact balance sheet}

The results of the environmental impact assessment can then be compared to the scaled PQs in the planetary accounts. An "impact balance statement" can be used show the impact and limit for each PQ currency, and thus the credit or deficit.

The idea of "credits" in each currency could be seen as encouragement to "optimise on the edge" - to push our impacts to the limits. However, we include this terminology intentionally. Currently, language around environmental impacts is often very negative. There is a focus on reducing bad as opposed to improving good. The concept of environmental credits could help to shift the conversation to a focus on improving environmental maintenance. It could also provide a mechanism to financially incentivise those who are remaining below their targets or creating a net positive outcome.

\section{Potential applications}

The right-hand side of Fig. 7 shows some of the ways planetary accounts could be used. The PAF could allow meaningful decisions to be made at different levels or sectors regarding policy, planning, technology, business operations, legislation, and behaviour. It could enable the incorporation of the economic value of environmental impacts and management into existing global economic structures. The Framework enables the practical application and communication of the Planetary Boundaries to different scales of human activity.

Table 4 Divisible and non-divisible Quotas

\begin{tabular}{ll}
\hline Divisible Quotas & Non-Divisible Quotas \\
\hline Carbon & Air Quality \\
Me-NO & Biodiversity \\
Forest & \\
Ozone & \\
Nitrogen & \\
Phosphorous & \\
Water & \\
\hline
\end{tabular}




\section{Discussion}

The planetary quotas in context

In the latest update of the Planetary Boundaries the authors [12] show that four of the nine Boundaries have been exceeded, and that two have not been measured. Global estimates (shown in Table 5) indicate that five of the Quotas are currently exceeded, one is on the threshold, and the remaining two are uncertain. The current global estimates are shown against each Quota in Table 4.

\section{Planetary quotas versus planetary boundaries}

The Planetary Quotas complement rather than replace the Planetary Boundaries. The relationship between the two sets of indicators can be compared to human health. If a person visits a doctor, the doctor might measure State indicators such as blood pressure, heart rate, weight, and liver function to assess his health. If he is not healthy, his doctor is likely to prescribe a course of action. This might include a maximum calorific intake, a minimum level of exercise, and the avoidance of some activities, such as smoking. The PBs provide an indication of planetary health. The PQs are the prescription for a healthy planet.

This means that meeting or exceeding PQs gives a different message to meeting or exceeding PBs. For example, we have exceeded the PBs for climate change. It would take decades of living within the PQs associated with climate change to return to within the PB for climate change. For PBs that have not yet been exceeded, the PQs give an indication of whether we are heading towards the limits, or are likely to remain within them.

Unlike the Boundaries, no "zone of uncertainty" has been included for the Quotas. The zone of uncertainty is included in the Boundary framework to account for the fact that the science is uncertain. The Quotas are intended for use in policy, the design of technology, regulations, and behaviour within communities, households and businesses. In keeping with the precautionary principle, we have thus set the Quotas according to the lower limits in the Planetary Boundary framework. Future work should include estimations of uncertainty around the Quota values.

\section{Global vs regional limits and impacts - an issue of scale}

Greenhouse gases have a long atmospheric lifetime and become well mixed in the atmosphere. This means it is of little importance where the gas is emitted. $1 \mathrm{~kg}$ of $\mathrm{CO}_{2}$ will have the same contribution to global warming wherever it is released.

This is not the case for all of the impacts that are considered within the PQs, for example water consumption or the release of nitrogen into the environment. It is not the case that $1 \mathrm{~kg}$ consumed or released in one location will have the same impacts as $1 \mathrm{~kg}$ consumed or released elsewhere. If we take a few thousand litres of water from a water source with abundant supply, the local impacts are likely negligible. Taking just a few litres from another, water poor source, may have disastrous local effects. The release of a kilogram of nitrogen in a sparse agricultural area will have less impact on the Earth system than in an intense agricultural zone with risks of ground water contamination.

In the example of water, some authors advocate for a weighted water footprint to incorporate the different impacts of consuming water from different locations. The premise is that water from water rich water bodies should be given less environmental weighting than water from water scarce water bodies. A unit of equivalent water has been proposed based on a water stress index

Table 5 Each of the Planetary Quotas is shown against the estimate current global status

\begin{tabular}{|c|c|c|}
\hline Planetary Quota & Control Variable and Global Limit & Estimate of Current Global Status \\
\hline Carbon & Net $\mathrm{CO}_{2}$ emissions $\leq-7.3 \mathrm{GtCO}_{2} / \mathrm{yr}$ & $\sim 36 \mathrm{GtCO}_{2} / \mathrm{yr} .[104]$ \\
\hline MeNox & Me-NO emissions $\leq 5.4 \mathrm{GtCO}_{2} \mathrm{e} / \mathrm{yr}$ & $\sim 11 \mathrm{GtCO}_{2} \mathrm{e} / \mathrm{yr} .^{\mathrm{a}}$ \\
\hline Forestland & Deforestation $\leq-11 \mathrm{Mha} / \mathrm{yr}$ & $6.5 \mathrm{Mha} / \mathrm{yr}[105]$ \\
\hline Aerosols & $0.04 \leq$ AODe $\leq 0.1$ & Data not available \\
\hline Ozone & Montreal gas emissions $\approx \leq 0$ ODPkgs/yr & Data not available \\
\hline Nitrogen & Net nitrogen released to the environment $\leq 62 \mathrm{Tg} / \mathrm{yr}$ & $\sim 150 \mathrm{Tg} / \mathrm{yr}[12]$ \\
\hline Phosphorous & Net phosphorus released to the environment $\leq 11 \mathrm{Tg} / \mathrm{yr}$ & $\sim 22 \mathrm{Tg} / \mathrm{yr}[12]$ \\
\hline Water & Net water consumption $\leq 8500 \mathrm{~km}^{3} / \mathrm{yr}$ & $\sim 8500 \mathrm{~km}^{3} / \mathrm{yr}^{\mathrm{c}}$ \\
\hline Biodiversity & Percentage disappearing fraction of species $\leq 1 \mathrm{E}-4 / \mathrm{yr}$ & $1 E-5-1 E-6 / y r^{d}$ \\
\hline Imperishable Waste & Net imperishable waste $\leq 0 \mathrm{~kg}$ & Data not available \\
\hline
\end{tabular}

${ }^{\mathrm{a}}$ Derived from [104]

b In 2016, 92\% of the world's population lived in areas that exceed the World Health Organisation ambient air quality guidelines [106]. This suggests this Quota (which is based on these guidelines) has been exceeded

'There is no indicator or limit proposed for the Planetary Boundary - novel entities. However, under the PQs this Boundary is addressed by proxy through the water Quota

${ }^{d}$ Based on background extinction rate of $100-1000$ extinctions per million per year [12] 
that is based on the availability and withdrawals of a given water body. [103]

The problem with this proposal is that the impacts assigned to a given withdrawal of water depend on withdrawals by others from the same water body. Whilst this may give a realistic measure of impacts, it does not offer a useful indicator for decision making and planning. A company which has put substantial effort into reducing water consumption could have their weighted water footprint doubled because an independent company starts to use the same water body. In the same way, if a large company set up and put local companies out of business thus eliminating their use of a water body, their weighted water footprint would go down, even if they had taken no steps at all to improve their water use efficiency. This is not consistent with other impacts that are assessed in terms of equivalency. For example, greenhouse gases are often measured in terms of equivalent $\mathrm{CO} 2$ emissions. The proposed new metric for aerosols discussed in the previous section uses the unit equivalent AOD. These equivalencies are not dependent on other actors. If a company emits $50 \mathrm{~kg}$ of nitrous oxide, this is equivalent to $14.9 \mathrm{t}$ of $\mathrm{CO} 2$ no matter what other companies are doing.

There is no question that the scarcity of a source of water should be considered when environmental impacts of an activity are assessed. However, we disagree with the water weighting approach as it is inconsistent with environmental accounting practises. There are other ways that regionality could be included in planetary accounts. For example, a binary water scarcity indicator (yes/no) could be reported alongside the net water footprint to convey the suitability of the water source. Regional issues for other environmental currencies could be included in a similar way. Further work should be undertaken to explore this.

Planetary Accounting is not intended as the one super-system to resolve all environmental problems. The purpose of Planetary Accounting is to allow humanity to manage human activity such that it does not push the Earth system into a new geological state. There are many local environmental problems that do not translate simply into planetary limits. For example, land instability and polluted waterways due to poor farming practices, light pollution, and the urban heat island effect. Planetary Accounting does not replace local environmental management practices created locally and solvable locally; these must be dealt with at a local level. The Planetary Boundaries and the PQ's derived from them are a context of limits that can be translated into action to solve these global constraints at various levels of activity.

\section{Timeframe}

The PQs show what is needed to return to and remain within the safe operating space of the PBs. They define an end goal rather than a pathway of reductions. There is no timeframe associated with any of the PQs except the PQ for $\mathrm{CO}_{2}$ emissions. This is because the $\mathrm{CO}_{2}$ budget is based on cumulative emissions so the longer we delay in achieving this $\mathrm{PQ}$, the more stringent it would need to be. However, at any time that any of the Quotas or Boundaries are not respected, humanity is at risk of departure from a Holocene-like state. We should work to live within the PQs as soon as possible and if like the climate change boundary we have exceeded them then we must rapidly get to work to reclaiming a safe-operating space.

\section{Comparing planetary quotas}

We have not proposed a mechanism to compare one Quota to another or to amalgamate the results of environmental assessments into a single indicator of sustainability. This is intentional. The Earth cannot amalgamate these environmental currencies or trade one for another. If we consume too much water, this cannot be resolved by emitting less carbon, though it is appreciated that there is a nexus between water and carbon. At a global scale, each of the Quotas must be respected if we are to operate within the Planetary Boundaries.

\section{The planetary quotas are a moving target not a static value}

The Earth system is dynamic and the rate of increase in scientific understanding of its processes and limits is high. There is not time to wait until we have a perfect understanding of the system or its limits before we take action to operate within these - this may never eventuate. The indicators and limits presented in this paper are intended to be preliminary. It is our intention that, like the Planetary Boundaries, these are subjected to scrutiny, discussion, and analysis, and are regularly reviewed and updated over time as we advance in our collective knowledge and understanding.

\section{Opportunities for planetary accounting in practice}

The PAF has been designed with a high degree of flexibility with the intention that this could enable a wide range of applications that go beyond those envisioned by the authors. Some of the applications it could be used for are discussed here.

\section{Economic value}

We have not included a mechanism to enable the trading of one PQ currency for another, however this does not preclude the opportunity to trade in each of the 
Quota currencies at lower scales. On the contrary, Planetary Accounting provides an opportunity for a global trading system for key global environmental "currencies" and in the process firms can see how these parameters interact and are synergistic. Moreover, the real costs to humanity of exceeding planetary limits - i.e. the costs of adaptation and mitigation - or the value of undershoot - i.e. the money not spent because nature provides a service - could be used to assign a monetary value to each environmental currency, for example $\$ \mathrm{X} / \mathrm{kg}$ of nitrogen. The true cost to society might only be known in hindsight. However, if values were assigned to each unit of environmental currency, companies could make money from the restoration and maintenance of Earth-system processes. Such an exercise could facilitate the incorporation of the environmental impacts into existing global economic frameworks thus enabling a further decoupling of wealth creation and environmental footprint [42].

\section{Behaviour change}

Behaviour change programmes such as a smart phone application could be based on the Planetary Quotas. In a live game, individuals could compete with friends and strangers across the globe to live within their share of the planet's limits. The same could be used by firms wanting to create a market for new design and technology products and services.

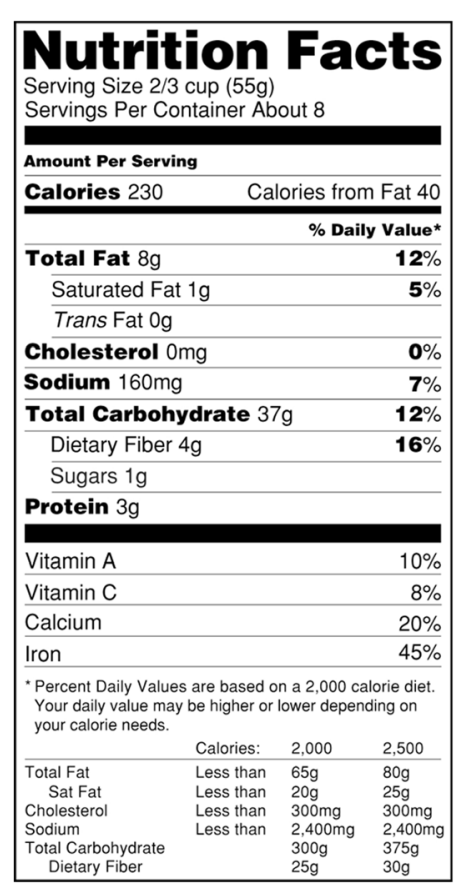

Fig. 8 Planetary Facts Labelling
To facilitate better producer and consumer responsibility, a product labelling system similar to the nutritional facts labelling system for food could be developed based on the Quotas (see Fig. 8). Whether this was displayed on products as part of a labelling system, or simply made available online, companies could use such a system to communicate the impacts of goods and services in different environmental currencies. A global labelling scheme could provide an opportunity to address the regional variation of some Quotas (such as the water Quota), discussed later.

Further work would be required to determine the appropriate format, inclusions, and exclusions for a labelling system such that it could be both accessible to a wide audience, and implementable for producers.

\section{Limitations}

One of the major limitations of the PAF is a lack of available data. It would not currently be possible for a person to determine the impacts of their consumption to compare against her PQ as it would be difficult to estimate the impacts of most of the products and services that she uses. A company seeking to understand the impacts of their products may not be able to obtain data on the impacts of the extraction of raw materials. The time and cost associated with obtaining the data needed for a detailed environmental impact assessment can often be prohibitive. The availability of data and simplification of environmental impact assessments will be an important area of future work to make planetary accounting feasible.

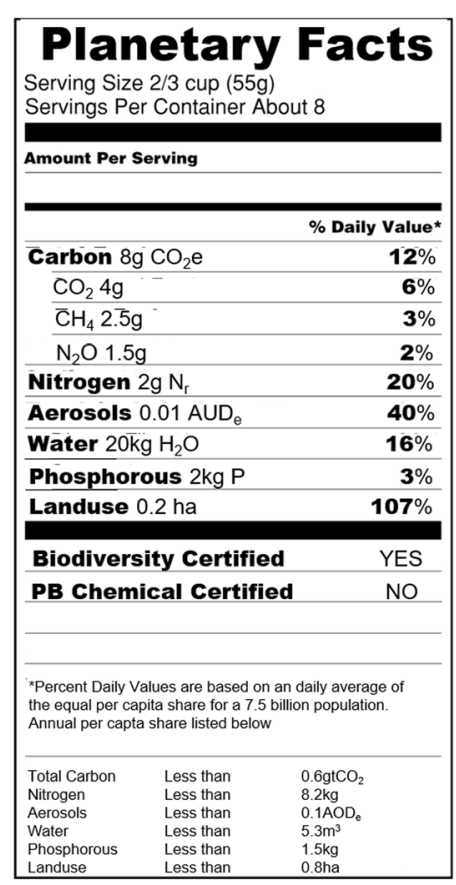


In many applications double counting of impacts is to be expected - for example the impacts of a person's consumption of a litre of milk would be counted in her accounts, the milk producer's accounts, the city's consumption-based accounts and the production accounts for the region where the milk was made. This sort of double counting is not a problem. However, if financial transactions are based on overshoot and undershoot, further work will be required to develop a system to manage double counting.

Another limitation of the PAF is that it has not yet been applied and evaluated as an instrument to guide policy, business, or behavioural decisions. In the development of the concept, and particularly of the framework, much effort was taken to envision the different applications to determine and address potential weaknesses of the system. However, there is no substitute for real world applications.

\section{Conclusions}

Humankind has the scientific knowledge needed to manage the Anthropocene and ensure a Holocene-like state of the environment is retained; but we will need to change as the limits expressed by the Planetary Boundaries are being approached or exceeded. There is evidence that a poly-scalar approach is the most effective change mechanism to manage the global commons through engaging different levels of human activity. Environmental accounting has advanced to the point that we can estimate what the environmental impacts of an activity are or will be. These three theories are advanced in the literature but are disconnected from one another. The Planetary Accounting Framework based on the new Planetary Quotas brings these three theories together.

Planetary Accounting is a novel framework that could facilitate an unprecedented, global, multi-scaled approach to managing the Earth system. There will undoubtedly be many ways to improve the system suggested here but this paper has started a process that can allow scientists and policy makers to work in a more concerted way to help create a future where the planet remains in the safe operating space.

\section{Endnotes}

${ }^{1}$ Manuscript in preparation.

\section{Additional files}

Additional file 1: Supplementary Information. (DOCX $115 \mathrm{~kb}$ )

Additional file 2: Decarbonisation Pathways. (JPG 62 kb)

\section{Abbreviations}

AODe: Aerosol Optical Depth equivalent; $\mathrm{CO}_{2}$ : Carbon dioxide; $\mathrm{CO}_{2} \mathrm{e}$ : Carbon dioxide equivalent; DPSIR: Driver-Pressure-State-Impact-Response; DU: Dobson Unit; E/MSY: Extinctions per million species per year; GHG: Greenhouse Gas; LCA: Life Cycle Assessment; Menox: Methane and
Nitrous Oxide; PAF: Planetary Accounting Framework; PB: Planetary Boundary; PPM: Parts per million; PQ: Planetary Quota

\section{Acknowledgements}

We acknowledge Alan Merry for his extensive feedback on early drafts of this manuscript.

Funding

Australian Postgraduate Award \& Curtin University Postgraduate Scholarship received by Kate Meyer as a PhD stipend for the duration of the research. Australia Domain Administration (AuDA) provided a top up scholarship for Kate Meyer for the duration of the research.

\section{Authors' contributions}

KM conceived of the study, developed the methodology, carried out the research and drafted the manuscript. PN provided senior guidance throughout the research and contributed to the final manuscript. Both authors read and approved the final manuscript.

Ethics approval and consent to participate

Not applicable.

Consent for publication

Not applicable.

\section{Competing interests}

The Editor-in-Chief of the journal, Peter Newman, is an author of this article. The content was independently reviewed by peers in the field and the decision to accept this article for publication was made by a member of the Editorial Board. Peter's position did not have any conscious influence on this decision. The authors declare that they have no competing interests.

\section{Publisher's Note}

Springer Nature remains neutral with regard to jurisdictional claims in published maps and institutional affiliations.

Received: 25 January 2018 Accepted: 20 July 2018

Published online: 25 October 2018

References

1. Skinner BJ. The blue planet : an introduction to earth system science / Brian J. Skinner, Barbara Murck. 3rd ed. Hoboken: Wiley; 2011.

2. Severinghaus JP, Sowers T, Brook EJ, Alley RB, Bender ML. Timing of abrupt climate change at the end of the younger Dryas interval from thermally fractionated gases in polar ice. Nature. 1998;391:141.

3. Hublin J, et al. Nature. 2017;546:289-92.

4. Rockström J, Steffen W, Noone K, Persson $\AA$, Chapin FS, Lambin EF, Lenton TM, Scheffer M, Folke C, Schellnhuber HJ, et al. A safe operating space for humanity. Nature. 2009;461:472-5.

5. Rockström J, Steffen W, Noone K, Persson A, Chapin FS, Lambin E, Lenton TM, Scheffer M, Folke C, Schellnhuber HJ, et al. Planetary boundaries: exploring the safe operating space for humanity. Ecol Soc. 2009;14:32.

6. Crutzen PJ. Geology of mankind. Nature. 2002;415:23.

7. Zalasiewicz J, Williams M, Haywood A, Ellis M. The Anthropocene: a new epoch of geological time? Philos Trans R Soc A Math Phys Eng Sci. 2011; 369:835-41.

8. IPCC. Summary for policymakers. In: Stocker TF, Qin D, Plattner G-K, Tignor M, Allen SK, Boschung J, Nauels A, Xia Y, Bex V, Midgley P, editors. Climate change 2013: the physical science basis contribution of working group I to the fifth assessment report of the intergovernmental panel on climate change. Cambridge and New York: Cambridge University Press; 2013.

9. IPCC. Climate Change 2013: The Physical Science Basis. Contribution of Working Group I to the Fifth Assessment Report of the Intergovernmental Panel on Climate Change. Cambridge, New York: Cambridge University Press; 2013.

10. Trenberth K. Volume 1, the earth system: physical and chemical dimensions of global environmental change. In: MacCracken MaP J, editor. Encyclopedia of Global Environmental Change. Chichester: Wiley; 2002. p. 1.

11. Loutre MF, Berger A. Future climatic changes: are we entering an exceptionally long interglacial? Clim Chang. 2000;46:61-90. 
12. Steffen W, Richardson K, Rockström J, Cornell SE, Fetzer I, Bennett EM, Biggs R, Carpenter SR, De Vries W, De Wit CA, et al. Planetary boundaries: guiding human development on a changing planet. Science. 2015;347:1259855.

13. Olson M. The Logic of Collective Action: Public Goods and the Theory of Groups. Cambridge: Harvard University Press; 1965.

14. Hardin G. The tragedy of the commons. Science. 1968;162:1243-8.

15. Gordon HS. The economic theory of a common-property resource: the fishery. J Polit Econ. 1954;62:124-42.

16. Ostrom E. Governing the commons : the evolution of institutions for collective action / Elinor Ostrom. Cambridge, New York: Cambridge University Press; 1990.

17. Brondizio ES, Ostrom E, Young OR. Connectivity and the Governance of Multilevel Social-Ecological Systems: The Role of Social Capital. Annu Rev Environ Resour. 2009;34:253-78.

18. Ostrom E. Polycentric systems for coping with collective action and global environmental change. Glob Environ Chang. 2010;20:550-7.

19. Liu L. A New Perspective for Combating Global Climate Change. Transnational Corporations Review. 2010;2:78-81.

20. Hari MO. I. Solving global problems: Perspectives from International law and policy: the geography of Solving global environmental problems: reflections on polycentric efforts to address climate change. NYL Sch L Rev. 2013;58:777-931.

21. Eon C, Morrison G, Byrne J. The influence of design and everyday practices on individual heating and cooling behaviour in residential homes. Energy Efficiency. 2018;11:273-93.

22. Steg $L$, Vlek C. Encouraging pro-environmental behaviour: an integrative review and research agenda. J Environ Psychol. 2009;29:309-17.

23. Steg L. Values, norms, and intrinsic motivation to act Proenvironmentally. Annu Rev Environ Resour. 2016;41:277-92.

24. Eon C, Morrison GM, Byrne J. Unraveling everyday heating practices in residential homes. Energy Procedia. 2017;121:198-205.

25. Newman P, Kenworthy J. The end of automobile dependence : how cities are moving beyond car-based planning. Washington: Island Press; 2015.

26. Bernard T, Young J. The ecology of Hope: communities collaborate for sustainability. Gabriola Island: New Society Publishers; 1997.

27. Freeman DM. Local level organizations for local development: concepts and cases of irrigation organization. Boulder: Westview Press; 1989.

28. Korten D. Introduction: community-based resource management. In: Korten D, editor. Community Management: Asian Experience and Perspectives. Hartford: Kumarian Press; 1987

29. Korten D, Klauss R. People Centred development: contributions toward theory and planning frameworks. Hartford: Kumarian Press; 1984.

30. McCay BJ, Acheson JM. The question of the commons. The culture and ecology of communal resources. Tucson: University of Arizona Press; 1987.

31. National Research Council. Proceedings of the Conference on Common Property Resource Management. Washington: National Academy Press; 1986.

32. Ostrom E. The rudiments of a theory of the origins, survival and performance of common property institutions. In: Korten D, editor. Making the Commons Work. Hartford: Kumarian Press; 1988.

33. Siy RY. Community resource management: lessons from the Zanjera. Manila: University of the Phillipines Press; 1982.

34. McKean M. Common Property: What Is It, What Is It Good For, and What Makes It Work? In: Gibson C, McKean M, Ostrom E, editors. Forest resources and institutions. Rome: The Food and Agriculture Organization of the United Nations; 1998.

35. Ostrom E. A polycentric approach for coping with climate change. Group DaER ed., vol. policy research working paper 5095. Washington: World Bank; 2009.

36. Newman P. Can the magic of sustainability revive environmental professionalism? Greener Management International. 2005;49:11-23.

37. Griffin M. Assumptions for success: a manager's use of McGregor's Y-theory assumptions produces significant changes in staff attitudes and performance. Nurs Manag (Harrow). 1988;19:32U-X.

38. Russ TL. Theory X/Y assumptions as predictors of managers' propensity for participative decision making. Manag Decis. 2011;49:823-36.

39. Kates R, Wilbanks T. Making the global local responding to climate change concerns from the ground. Environ: Sci Policy for Sustainable Dev. 2003;45:12-23.

40. Moll HC, Noorman K, Kok R, Engström R, Throne-holst H, Clark C. Pursuing more sustainable consumption by analyzing household metabolism in European countries and cities. J Ind Ecol. 2005;9:259-75.

41. Neuvonen A, Kaskinen T, Leppänen J, Lähteenoja S, Mokka R, Ritola M. Lowcarbon futures and sustainable lifestyles: a backcasting scenario approach Futures. 2014;58:66-76.
42. Newman P, Beatley T, Boyer H. Resilient cities. 2nd ed. Washington DC: sland Press/Center for Resource Economics; 2017.

43. Enker R. Energy policy for buildings: Why economic interventions may be ineffective. In: CESB 2016 - Central Europe Towards Sustainable Building 2016: Innovations for Sustainable Future; 2016. p. 1366-73.

44. Enker RA, Morrison GM. Analysis of the transition effects of building codes and regulations on the emergence of a low carbon residential building sector. Energy and Buildings. 2017;156:40-50.

45. Galaz V, Crona B, Österblom H, Olsson P, Folke C. Polycentric systems and interacting planetary boundaries - emerging governance of climate changeocean acidification-marine biodiversity. Ecol Econ. 2012;81:21-32.

46. The Brundtland Commission: Our Common Future. World Commission on Environment and Development; 1987.

47. The Paris Agreement [https://unfccc.int/process/conferences/pastconferences/ paris-climate-change-conference-november-2015/paris-agreement].

48. Murray A, Skene K, Haynes K. The circular economy: an interdisciplinary exploration of the concept and application in a global context. J Bus Ethics. 2017;140:369-80.

49. Ewing B, Moore D, Goldfinger S, Ourslet A, Reed A, Wackernagel M. Ecological footprint atlas 2010. Global Footprint Network: Oakland; 2010.

50. Global Footprint Network: National Footprint Accounts, 2014 edition. 2014.

51. Footprint Calculator [http://footprintnetwork.org/en/index.php/GFN/page/ calculators/].

52. Cucek L, Klemes JJ, Kravanja Z. A review of footprint analysis tools for monitoring impacts on sustainability. J Clean Prod. 2012;34:9-20.

53. Fang K. Footprint family: current practices, challenges and future prospects. Shengtai Xuebao/ Acta Ecologica Sinica. 2015;35:7974-86.

54. Fang K, Heijungs R, De Snoo GR. Theoretical exploration for the combination of the ecological, energy, carbon, and water footprints: overview of a footprint family. Ecol Indic. 2014;36:508.

55. Galli A, Wiedmann T, Ercin E, Knoblauch D, Ewing B, Giljum S. Integrating ecological, carbon and water footprint into a "footprint family" of indicators: definition and role in tracking human pressure on the planet. Ecol Indic. 2012;16:100-12.

56. Čuček L, Klemeš JJ, Kravanja Z. Overview of environmental footprints. In: Assessing and Measuring Environmental Impact and Sustainability; 2015. p. 131-93.

57. Laurent A, Owsianiak M. Potentials and limitations of footprints for gauging environmental sustainability. Curr Opin Environ Sustain. 2017; 25:20-7.

58. Akenji L, Bengtsson M, Bleischwitz R, Tukker A, Schandl H. Ossified materialism: introduction to the special volume on absolute reductions in materials throughput and emissions. J Clean Prod. 2016;132:1-2.

59. Arvidsson R, Kushnir D, Molander S, Sandén BA. Energy and resource use assessment of graphene as a substitute for indium tin oxide in transparent electrodes. J Clean Prod. 2016;132:289-97.

60. Hertwich EG. Consumption and the rebound effect: an industrial ecology perspective. J Ind Ecol. 2005:9:85-98.

61. Kojima S, Aoki-Suzuki C. Efficiency and fairness of resource use: from a planetary boundary perspective. In: The Economics of Green Growth: New Indicators for Sustainable Societies; 2015. p. 31-48.

62. Fong WK, Sotos M, Doust M, Schultz S, Marques A, Deng-Beck C. Global protoco for community-scale greenhouse gas emission inventories - an accounting and reporting standard for cities. In: Greenhouse Gas Protocol. USA: World Resources Institute, C40 Cities, and Local Governments for Sustainability; 2014.

63. Greenhalgh S, Broekhoff D, Daviet F, Ranganathan J, Acharya M, Corbier L, Oren K, Sundin H. The GHG protocol for project accounting. In: Greenhouse Gas Protocol. USA: World Resources Institute and World Business Council for Sustainable Development; 2005.

64. Newman P. The rise and rise of renewable cities. Renewable Energy and Environmental Sustainability. 2017;2:10

65. IEA. World Energy Outlook, special report on energy and air quality. Paris: IEA; 2017

66. Le Quéré $C$, Andrew RM, Friedlingstein P, Sitch S, Pongratz J, Manning AC, Korsbakken JI, Peters GP, Canadell JG, Jackson RB, et al. Global carbon budget 2017. Earth Syst Sci Data Discuss. 2017:2017:1-79.

67. Cole MJ, Bailey RM, New MG. Tracking sustainable development with a national barometer for South Africa using a downscaled "safe and just space" framework. Proc Natl Acad Sci U S A. 2014;111:E4399-408.

68. Fang K, Heijungs R, De Snoo GR. Understanding the complementary linkages between environmental footprints and planetary boundaries in a footprint-boundary environmental sustainability assessment framework. Ecol Econ. 2015;114:218-26 
69. Sandin G, Peters GM, Svanström M. Using the planetary boundaries framework for setting impact-reduction targets in LCA contexts. Int J Life Cycle Assess. 2015;20:1684-700.

70. Dao H, Peduzzi P, Chatenoux B, De Bono A, Schwarzer S, Friot D. Environmental limits and Swiss footprints based on planetary boundaries. Geneva: UNEP/GRID-Geneva \& University of Genever; 2015.

71. Hoff H, Nykvist B, Carson M. "Living well, within the limits of our planet?" Measuring Europe's growing external footprint. In: SEl Working Paper 2014-05. Stockholm: Stockholm Environment Institute; 2014.

72. Nykvist B, Persson Å, Moberg F, Persson LM, Cornell SE, Rockström J. National Environmental Performance on planetary boundaries: a study for the Swedish Environmental Protection Agency. Sweden: Agency SEP; 2013

73. EEA. EEA core set of indicators. Guide. Luxembourg: Technical report no 1/ 2005; 2005.

74. Häyhä T, Lucas PL, van Vuuren DP, Cornell SE, Hoff H. From planetary boundaries to national fair shares of the global safe operating space how can the scales be bridged? Glob Environ Chang. 2016;40:60-72.

75. ISO. ISO 14040:1997 environmental management - life cycle assessment principles and framework. Geneva: ISO; 1997.

76. Hansen J, Sato M, Kharecha P, Beerling D, Berner R, Masson-Delmotte V, Pagani M, Raymo M, Royer DL, Zachos JC. Target atmospheric CO2: where should humanity aim? Open Atmos Sci J. 2008;2:217-31.

77. IPCC. Annex II: Climate System Scenario Tables. In: Stocker TF, Qin D, Plattner G-K, Tignor M, Allen SK, Boschung J, Nauels A, Xia Y, Bex V, Midgley PM, editors. Climate Change 2013: The Physical Science Basis Contribution of Working Group I to the Fifth Assessment Report of the Intergovernmental Panel on Climate Change. Cambridge, New York: Cambridge University Press; 2013. p. 1395-446. Prather M, Flato G, Friedlingstein $\mathrm{P}$, Jones $\mathrm{C}$, Lamarque J-F, Liao H, Rasch P (Series Editor).

78. Rockström J, Gaffney O, Rogelj J, Meinshausen M, Nakicenovic N, Schellnhuber HJ. A roadmap for rapid decarbonization. Science. 2017;355:1269-71.

79. Obersteiner M, Bednar J, Wagner F, Gasser T, Ciais P, Forsell N, Frank S, Havlik $P$, Valin $H$, Janssens IA, et al. How to spend a dwindling greenhouse gas budget. Nat Clim Chang. 2018;8:7-10.

80. Deforestation [http://worldwildlife.org/threats/deforestation].

81. Chin M. Atmospheric aerosol properties and climate impacts: DIANE Publishing; 2009

82. de Vries W, Kros J, Kroeze C, Seitzinger SP: Assessing planetary and regional nitrogen boundaries related to food security and adverse environmental impacts. Curr Opin Environ Sustain 2013, 5:392-402.

83. Mekonnen MM, Hoekstra AY. The green, blue and grey water footprint of crops and derived crop products. Hydrol Earth Syst Sci. 2011;15:1577-600.

84. Hoekstra AY. Water footprint assessment: evolvement of a new research field. Water Resour Manag. 2017:1-21.

85. Ridoutt B, Pfister S. A new water footprint calculation method integrating consumptive and degradative water use into a single stand-alone weighted indicator. Int J Life Cycle Assess. 2013;18:204-7.

86. Galli A, Wackernagel M, Iha K, Lazarus E. Ecological footprint: implications for biodiversity. Biol Conserv. 2014;173:121-32.

87. Secretariat of the CBD. Global biodiversity outlook 4. Montreal: Convention on Biological Diversity; 2014.

88. MEA. Ecosystems and Human Well-Being: Biodiversity Synthesis. Washington: World Resources Institute; 2005.

89. CBD. Pathways of introduction of invasive species, their prioritization and management. Montreal: UNEP, Convention on biological diversity; 2014.

90. Secretariat of the CBD. Global biodiversity outlook 3. Montreal: Secretariat of the Convention on Biological Diversity; 2010

91. Fahrig L. How much habitat is enough? Biol Conserv. 2001;100:65-74.

92. Groombridge B. Global biodiversity : status of the earth's living resources : a report / compiled by the world conservation monitoring Centre. London: Chapman \& Hall; 1992.

93. Bibby CJ. Recent past and future extinctions in birds. Phil Trans R Soc Lond B. 1994;344:35-40.

94. Ehrlich PR. Energy use and biodiversity loss. Phil Trans R Soc Lond B. 1994; 344:99-104.

95. Thomas JA, Morris MG, Hambler C. Patterns, mechanisms and rates of extinction among invertebrates in the United Kingdom [and discussion] Phil Trans R Soc Lond B. 1994;344:47-54.

96. Wackernagel $M$, Schulz NB, Deumling $D$, Linares AC, Jenkins $M$, Kapos $V$, Monfreda C, Loh J, Myers N, Norgaard R, Randers J. Tracking the ecological overshoot of the human economy. Proc Natl Acad Sci U S A. 2002;99:9266-71.
97. Soulé ME, Sanjayan MA. ECOLOGY: conservation targets: do they help? Science (New York). 1998:279:2060-1.

98. Margules CR, Nicholls AO, Pressey RL. Selecting networks of reserves to maximise biological diversity. Biol Conserv. 1988;43:63-76.

99. UNEP: Global guidance for life cycle impact assessment indicators. Frischknecht R, Jolliet O eds. Nairobi: UNEP; 2016.

100. Tyree C, Morrison D: Invisibles: the plastic inside us. Orbmedia.org; 2017.

101. Ciais P, Sabine C, Bala G, Bopp L, Brovkin V, Canadell J, Chhabra A, DeFries R, Galloway J, Heimann M, et al. Carbon and other biogeochemical cycles. In: Stocker TF, Qin D, Plattner G-K, Tignor M, Allen SK, Boschung J, Nauels A, Xia Y, Bex V, Midgley PM, editors. Climate change 2013: the physical science basis contribution of working group I to the fifth assessment report of the intergovernmental panel on climate change. Cambridge, New York: Cambridge University Press; 2013. p. 465-570.

102. Mercury Levels in Commercial Fish and Shellfish (1990-2012) [https://www. fda.gov/Food/FoodbornelllnessContaminants/Metals/ucm115644.htm].

103. Ridoutt $\mathrm{BG}$, Pfister S. A revised approach to water footprinting to make transparent the impacts of consumption and production on global freshwater scarcity. Glob Environ Chang. 2010;20:113-20.

104. CO2 Emissions (metric tons per capita) [http://data.worldbank.org/indicator/ EN.ATM.CO2E.PC?order=wbapi_data_value_2009\%20wbapi_data_ value\%20wbapi_data_value-last\&sort=asc].

105. FAO: Global Forest resources assessment 2015. Nations FaAOotU ed. Rome; 2016

106. WHO. In: World Health Organisation, editor. Ambient air pollution: a global assessment of exposure and burden of disease. Geneva: WHO Press; 2016.

\section{Ready to submit your research? Choose BMC and benefit from:}

- fast, convenient online submission

- thorough peer review by experienced researchers in your field

- rapid publication on acceptance

- support for research data, including large and complex data types

- gold Open Access which fosters wider collaboration and increased citations

- maximum visibility for your research: over $100 \mathrm{M}$ website views per year

At $\mathrm{BMC}$, research is always in progress.

Learn more biomedcentral.com/submissions 